\title{
Composite Structure Modeling and Analysis of Advanced Aircraft Fuselage Concepts
}

\author{
Vivek Mukhopadhyay ${ }^{1}$ and Michael R. Sorokach ${ }^{2}$ \\ Aeronautical Systems Analysis Branch, \\ 442/NASA Langley Research Center, Hampton, VA 23681
}

\begin{abstract}
NASA Environmentally Responsible Aviation (ERA) project and the Boeing Company are collabrating to advance the unitized damage arresting composite airframe technology with application to the Hybrid-Wing-Body (HWB) aircraft. The testing of a HWB fuselage section with Pultruded Rod Stitched Efficient Unitized Structure (PRSEUS) construction is presently being conducted at NASA Langley. Based on lessons learned from previous HWB structural design studies, improved finite-element models (FEM) of the HWB multibay and bulkhead assembly are developed to evaluate the performance of the PRSEUS construction. In order to assess the comparative weight reduction benefits of the PRSEUS technology, conventional cylindrical skin-stringer-frame models of a cylindrical and a double-bubble section fuselage concepts are developed. Stress analysis with design cabin-pressure load and scenario based case studies are conducted for design improvement in each case. Alternate analysis with stitched composite hat-stringers and C-frames are also presented, in addition to the foam-core sandwich frame and pultruded rod-stringer construction. The FEM structural stress, strain and weights are computed and compared for relative weight/strength benefit assessment. The structural analysis and specific weight comparison of these stitched composite advanced aircraft fiselage concepts demonstrated that the pressurized HWB fuselage section assembly can be structurally as efficient as the conventional cylindrical fuselage section with composite stringer-frame and PRSEUS construction, and significantly better than the conventional aluminum construction and the double-bubble section concept.
\end{abstract}

\section{Nomenclature}

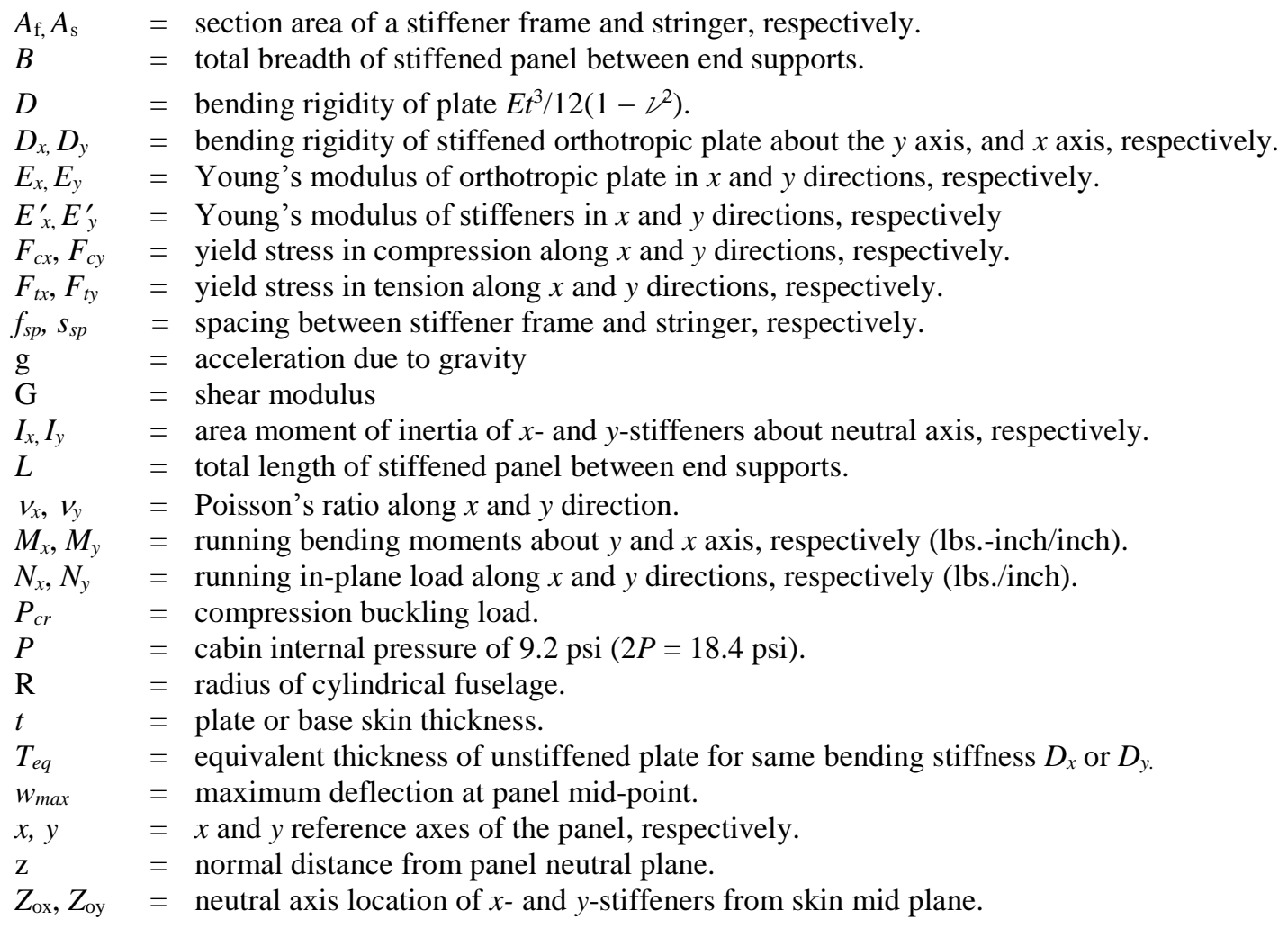

\footnotetext{
${ }^{1}$ Aerospace Engineer, Aeronautical Systems Analysis Branch, MS 442, AIAA Associate Fellow.

${ }^{2}$ Aerospace Engineer, Aeronautical Systems Analysis Branch, MS 442, AIAA Member.
} 


\section{Introduction}

$P$

ressurized fuselage configuration design for the unconventional Hybrid-Wing-Body ${ }^{1-3}$ (HWB) and Advanced Mobility Concept ${ }^{4}$ flight vehicles are significantly high-risk compared to the conventional stringer-frame cylindrical fuselage, due to the significantly higher bending stresses ${ }^{5}$, and structural deformation. Many novel structural concepts such as the ribbeddouble-shell, multi-bubble stiffened shell, thick composite sandwich shell, and recently the Pultruded Rod Stitched Efficient Unitized Structure (PRSEUS) construction have been studied under the NASA Environmentally Responsible Aviation (ERA) research project ${ }^{6-17}$ in collaboration with the Boeing Company.

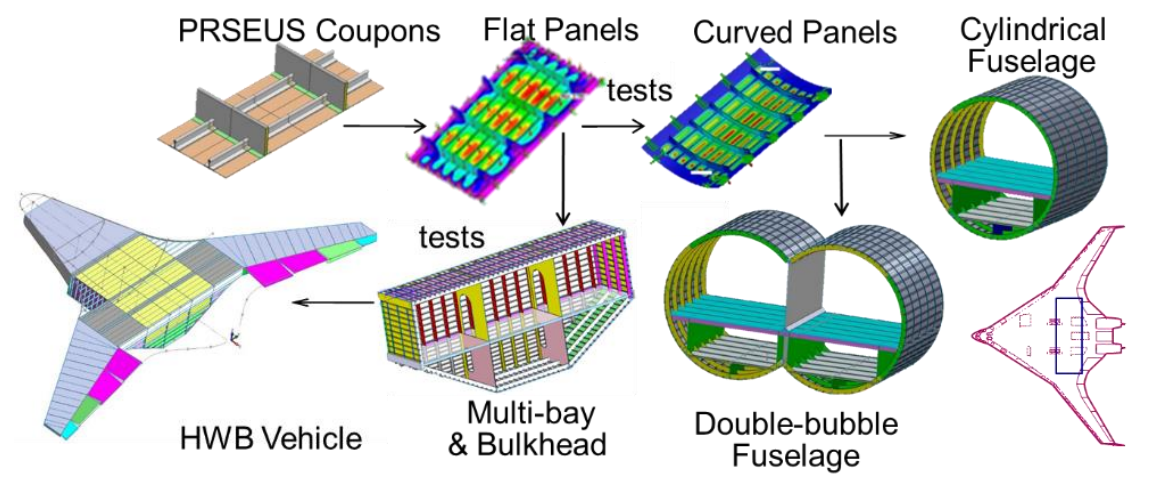

Figure 1. PRSEUS technology development roadmap for the Hybrid-Wing-Body (HWB) vehicle concept.

Figure 1 shows a schematic diagram of the PRSEUS technology development, starting with test coupons, flat and curved PRSEUS panels and progressing towards a HWB fuselage section construction at the Boeing Company and follow-up testing under way at NASA Langley Research Center. Initially detailed finite element models of PRSEUS coupons, flat panels and curved panels were developed and compared with test results of fabricated articles ${ }^{10-12}$. Structural analysis of the HWB conceptual vehicles for 100, 200, 300, and 400-passengers were presented by Gern ${ }^{14-15}$, in order to optimize the full vehicle structural weight at critical design load conditions. The most recent structural analysis of the HWB multi-bay fuselage section test article was presented by Przekop ${ }^{16}$. An integrated multi-bay fuselage and bulkhead finite element models (FEM) with flat PRSEUS panels were developed and analyzed for an independent case study and weight estimation ${ }^{13,17}$. In this paper, the PRSEUS modeling and analyses are applied to a representative cylindrical pressurized fuselage section and a multi-bubble section fuselage for comparison with the HWB concept. Several alternate concepts, which combine sandwich foam-core frame and hat-stringers, as well as conventional extruded frames and hat-stringers are also modeled and analyzed for structural weight/strength benefit analysis.

\section{Multi-bay analysis.}

Figure 2 shows an improved multi-bay concept model along with the sandwich frame and rod-stringer dimensions. This conceptual model is similar in geometry, compared to the engineering analysis of the test article described in Ref. 16, but many construction features are simplified in order to perform multiple design alternatives studies. This $70 \%$ scale HWB multi-bay box model is $360 \mathrm{inch}$ wide in the spanwise direction with a height of $162 \mathrm{in}$. and a chord-wise length of $80 \mathrm{in}$. The fuselage section has only four foam-core sandwich frames with spacing increased from 20 to 24 in. The 6 in. high sandwich frames have 0.5 inch thick foam-core, and are wrapped with two stack (0.104 in.) composite laminate. The frame flanges are stitched to skin and frame base cover straps. The rod-stringers are spaced 6 in. apart on top surface of each bay, on the side rib walls, and on the lower cargo bays and are modeled with beam elements. The passenger floor rod-stringers are spaced at 8 inch apart, since they carry mostly passenger weight. The two mid-cabin sandwich walls are modeled with 2 in. thick foamcore sandwich and 0.052 in. composite skin without cutouts. The four critical design load cases are as follows.

Load case 1. 18.4-psi internal static over-pressure at ground level (2P over pressure).

Load case 2. $2.5 \mathrm{~g}$ climb condition with the cabin operational pressure of $9.2 \mathrm{psi}(1 \mathrm{P}+2.5 \mathrm{~g})$

Load case 3. $-1 \mathrm{~g}$ dive condition with the cabin operational pressure of 9.2 psi (1P-1g)

Load case 4. Linear buckling analysis with load cases 2 and 3 (Buckling).

Out of the four load cases, the 2P over-pressure condition is critical for the HWB type flat structure static test certification. The bending due to the cabin pressure results in significantly higher stress compared to a conventional cylindrical fuselage 
that counters cabin pressure with membrane hoop stress. The maximum aerodynamic load for the $1 P+2.5 g$ case also produces a maximum compression load on the fuselage crown panels and a maximum tensile load on the fuselage keel panels. This bending load is idealized as approximately 5000-lb/in. running compression and tension load along the top and bottom panels, respectively. This in-plane ultimate design load was derived from full-vehicle FEM analysis ${ }^{8}$. Based on the composite material elastic properties for the orthotropic skin and frame wraps, the allowable maximum strains are 0.0059 in tension and 0.0048 in compression. On the rod-stringer, the maximum allowable strain is 0.007 in tension and 0.0058 in compression. The initial basic panel model component sizing and stress analyses were conducted using classical stiffened plate theory ${ }^{18-19}$. In this paper, finite element modeling and analyses were conducted with the SolidWorks Finite Element Simulation software ${ }^{20}$. The parametric case studies with frame spacing (20 and 24 inch) and stiffener spacing (6 and 8 inch) were conducted in Ref. 17. In this paper, 0.104 inch minimum gauge skin ( 2 stacks), 24 inch frame spacing, and 8 inch rodstringer spacing (both with two stack wraps) were recommended for a 90x140 panel with 2P over-pressure load condition.

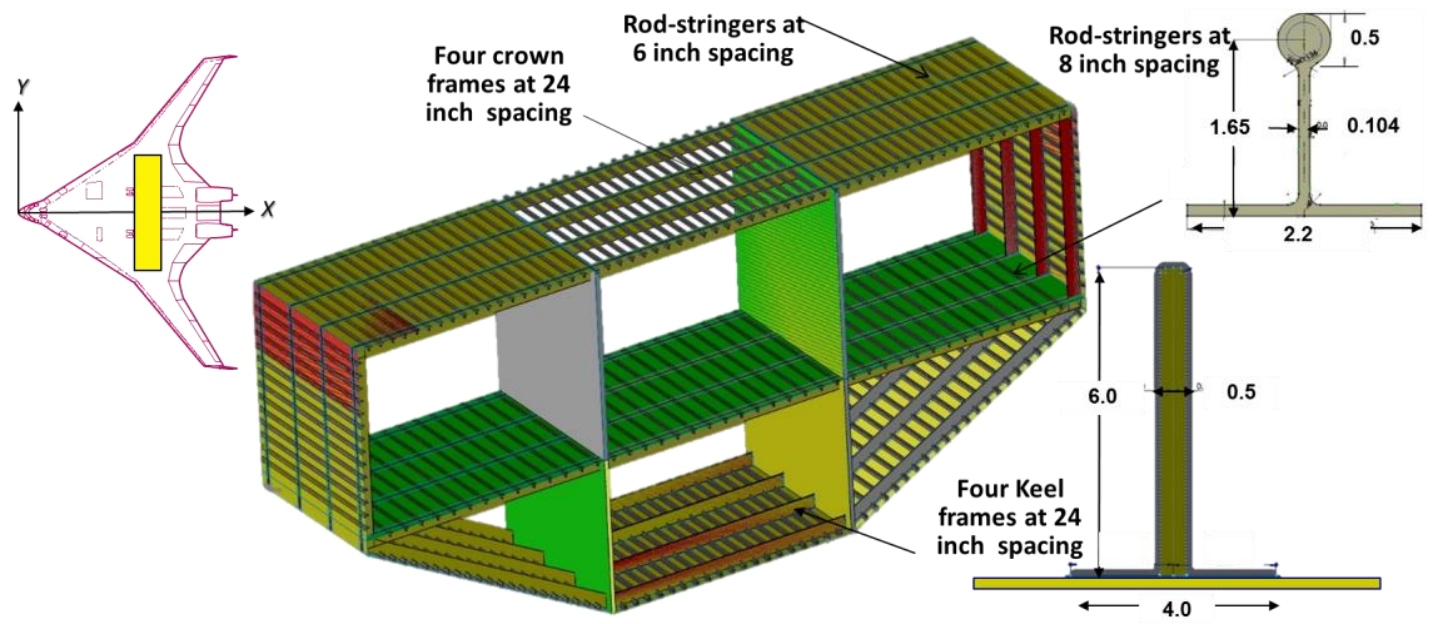

Figure 2. A multi-bay hybrid wing body fuselage section configuration model with four frames, and 8 inch rod-stringer spacing on crown surface.

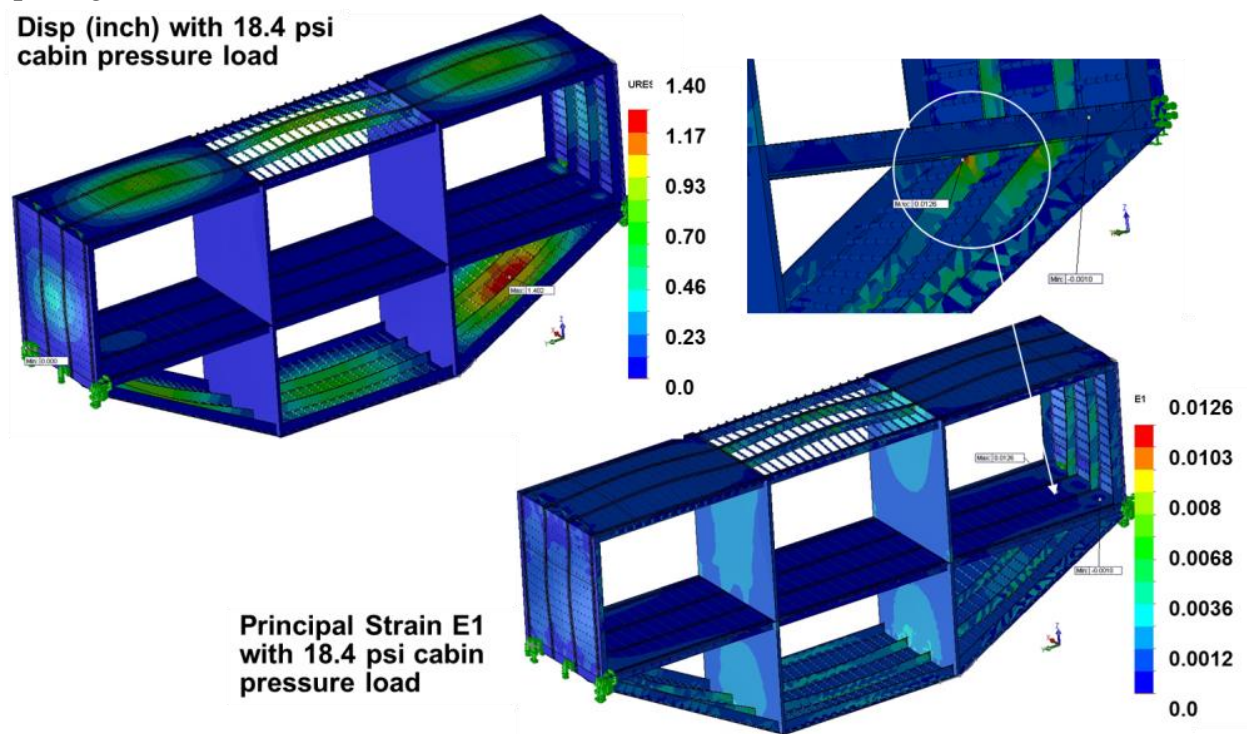

Figure 3. Four-frame multi-bay model displacement and element principal strain E1 under internal cabin pressure of 18.4 psi and passenger-floor pressure of $1 \mathrm{psi}$.

The details of the finite element model, frame and rod-stringer are also shown in Figure 2. The four sandwich frames are at 24 inch spacing. The foam-cores are modeled with solid elements. The two stack outer frame wraps and flanges are modeled with shell elements. The rod-stringers are at 6 inch spacing on the top crown and bottom keel surfaces. The rodstringers are at 8 inches apart on the passenger floor. All rod-stringers are modeled as beam elements. Structural deflections and first principal stresses with 18.4 psi internal pressure are shown in Figure 3. The maximum deflection of 1.4 inch occurs at the largest side-keel panels. The maximum deflection on the crown panel is about 1 inch. At the normal operational cabin 
pressure of $9.2 \mathrm{psi}$, this will cause a pillowing of the aerodynamic surface with maximum deflection about 0.5 inch at the center of the panel. The corresponding adverse effect on the aerodynamic flow, such as boundary layer separation, turbulence and increased drag are not known and should be a subject of future research. The principal stresses are generally within the allowable limits except at the joints between the side walls and the main passenger floor and also on cargo keel surfaces. These complex joints would require local corner braces or gusset plates in order to preclude local failure. In the actual test article FEM modeling and analysis ${ }^{16}$, the skin is reinforced gradually with layups from 2 to 10 stacks of woven stitched composite, and are seamlessly integrated into the flanges for attachment with side walls or ribs.

Table 1. Finite Element Model weight breakdown of the PRSEUS Multi-bay box section.

\begin{tabular}{|c|c|c|c|c|c|c|c|c|c|c|}
\hline $\begin{array}{l}\text { 1. BAY6A New weight calcula } \\
4 \text { frames @24 in. \& rods @6, }\end{array}$ & $\begin{array}{l}\text { with } 2 \text { st } \\
\text { nch spaci }\end{array}$ & $\begin{array}{l}\text { ack wra } \\
\text { ing with }\end{array}$ & $\begin{array}{l}\text { ap }(80 \mathrm{in} \\
1.652 \mathrm{w}\end{array}$ & base-rod & $\begin{array}{l}4 \text { frame ve } \\
\text { center } 2.1\end{array}$ & $\begin{array}{l}\text { ersion) } \\
1 \text { in flange }\end{array}$ & $3.4 \mathrm{in} \mathrm{fr}$ & $\begin{array}{l}120+120 \\
\text { rame stra }\end{array}$ & $\begin{array}{l}0+120 \\
\text { ap }\end{array}$ & \\
\hline BAY6A New weight calculatio & width/ses & length & area & thickness & vol. & density & wt/item & & weights & Group \\
\hline Study-2 & inch & in & in^2 & in & in^3 & $\mathrm{lb} / \mathrm{in}^{\wedge} 3$ & lbs & $x$ no item & llbs & weight \\
\hline skin group & & & & 1 and $2 \mathrm{st}$ & tack skin I & mixed & & & & 491 \\
\hline 3 top panels & 80 & 120 & 9600 & 0.104 & 998 & 0.057 & 57 & 3 & 171 & \\
\hline 2 side panel & 80 & 96 & 7680 & 0.052 & 399 & 0.057 & 23 & 2 & 46 & \\
\hline 3 floor panels & 80 & 120 & 9600 & 0.052 & 499 & 0.057 & 28 & 3 & 85 & \\
\hline bottom Keel panel & 80 & 120 & 9600 & 0.104 & 998 & 0.057 & 57 & 1 & 57 & \\
\hline$R+L$ keel panels & 80 & 140 & 11200 & 0.104 & 1165 & 0.057 & 66 & 2 & 133 & \\
\hline modified rod 1.65 inch b2c & rod area & web art & flange a & area & length & density & & no of rod & & \\
\hline rod-stringer group & in^2 & in^2 & in^2 & in^2 & in^3 & $\mathrm{Ib} / \mathrm{in}^{\wedge} 3$ & lbs & $x$ no & & 593 \\
\hline rod stringer C 8 in spacing & 0.20 & 0.13 & 0.22 & 0.55 & 80 & 0.057 & 2.5 & 143 & 358 & \\
\hline rod_stringer D@6 in 2 wrap & 0.27 & 0.26 & 0.33 & 0.86 & 80 & 0.057 & 3.9 & 60 & 234 & \\
\hline Mod Frame group @24 & width & length & area & thickness & $\mathrm{vol}$ & 120 and 2 & 200wf SI & $x$ no & & 1000 \\
\hline 2 frame core Rohacell 200 & 6 & 120 & 720 & 0.5 & 360 & 0.008 & 2.9 & 19 & 54 & \\
\hline 4 frame wrap+flanges & 15.9 & 120 & 1908 & 0.104 & 198 & 0.057 & 11.3 & 37 & 422 & \\
\hline side rib frame core & 6 & 96 & 576 & 0.5 & 288 & 0.004 & 1.2 & 8 & 9 & \\
\hline side rib core wrap+flange & 15.9 & 96 & 1526 & 0.104 & 159 & 0.057 & 9.0 & 8 & 72 & \\
\hline frame cover strap & 4.5 & 120 & 540 & 0.052 & 28 & 0.057 & 1.6 & 37 & 60 & \\
\hline end double frames Fib glass & 6 & 120 & 720 & 0.5 & $360^{\prime}$ & 0.057 & 20.5 & 19 & 383 & \\
\hline Inter cabin wall group & & & & & & & & & & 236 \\
\hline inter cabin core & 80 & 162 & 12960 & 0.396 & 5132 & 0.008 & 41.1 & 2 & 82 & \\
\hline inter cabin wrap & 80 & 162 & 12960 & 0.052 & 674 & 0.057 & 38.4 & 4 & 154 & \\
\hline Total weight (lb) & & & & & & & & & 2320 & 2320 \\
\hline Projected Surface area with & ab wall ar & & 129911 & in^2 & 902 & sq feet & & $\mathrm{Ib} / \mathrm{sq} \mathrm{ft}$ & 2.57 & \\
\hline without int-cab wall area & & & 103991 & in^2 & 722 & sq feet & & $\mathrm{Ib} / \mathrm{sq} \mathrm{ft}$ & 2.89 & \\
\hline
\end{tabular}

Table 1 shows initial breakdown of the structural weight components for the HWB multi-bay fuselage section. With two stack (0.104 inch) outer skin and single stack (0.052 inch) skin on side walls, the skin group weight is $491 \mathrm{lbs}$. Rod-stringers weight is $593 \mathrm{lbs}$. with 6 inch spacing on the highly loaded outer skin, and 8 inch spacing on the passenger floor and side rib walls. The frame group which carry and transfer most of the pressure load from the skin to the stringers have a total weight of $1000 \mathrm{lbs}$. The two inter-cabin wall weight total is $236 \mathrm{lbs}$. Thus total FEM weight is $2320 \mathrm{lb}$. The specific FEM structural weight, which is defined as the total FEM structural weight normalized by the total surface area for relative comparison with each of the construction concept is $2.57 \mathrm{lbs}$. In general all the attachments, bolts and fail-safe splices may add about $30 \%$ additional weight. The non-optimal weights such as the resin filling, paint and sealing may contribute an additional $20 \%$ weight.

Integrated multi-bay box and bulkhead assembly with horizontal frame: In preparation for extending the multibay model to the full center section passenger bay, design changes were made in the bulkhead frame orientation. Although in the test article, the bulkhead frames were vertical ${ }^{16}$, horizontal spanwise frames are advantageous for integration into the full vehicle outer wing. This spanwise frame orientation would allow efficient transfer of load from the outer wing rear spar into the rear bulkhead. Analysis results of the multi-bay and improved bulkhead assembly with spanwise frames are presented in Figure 4, which shows displacement and first principal strain under $18.4 \mathrm{psi}$ internal cabin pressure. In this analysis model, all sandwich frames are at 24 inch spacing, and all rod-stringers are at 8 inch spacing. Both are modeled as beam elements. The outer skin thickness is $0.104 \mathrm{inch}$. The maximum deflection (pillowing) of the crown surface is about 0.9 inch and maximum deflection of the cargo keel surface is about $1.18 \mathrm{inch}$. The maximum first principal strain is $0.006 \mathrm{inch} / \mathrm{inch}$ at the joints and are generally under 0.004 inch/inch in most areas. These deflections are $15 \%$ lower, compared to deflection results shown in Figure 4. This may be due to the beam cores being modeled as solid elements and absence of the bulkhead and corresponding changed edge boundary conditions. 

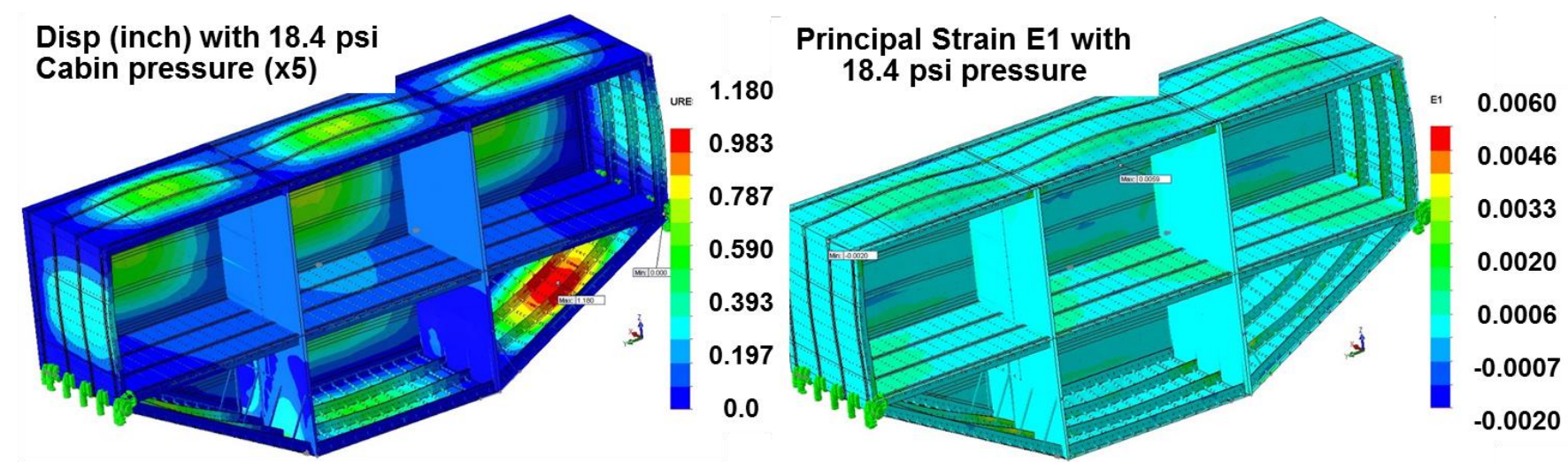

Figure 4. Integrated multi-bay and bulkhead model deflection and first principal stress distribution under 18.4 psi internal cabin pressure.

\section{Cylindrical Fuselage Analysis.}
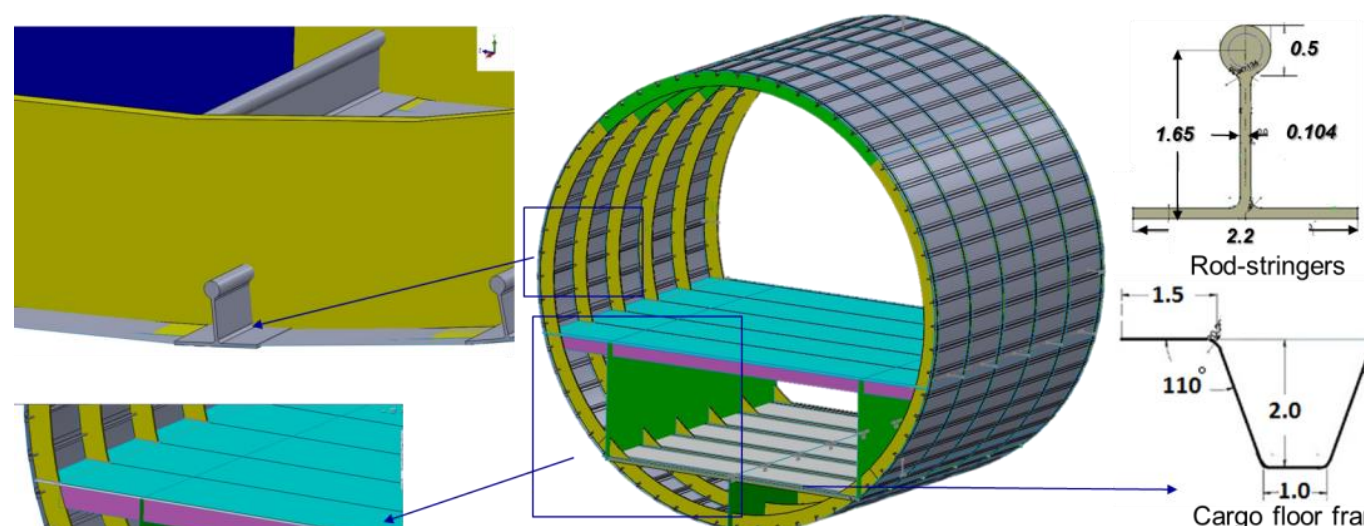

Rod-stringers

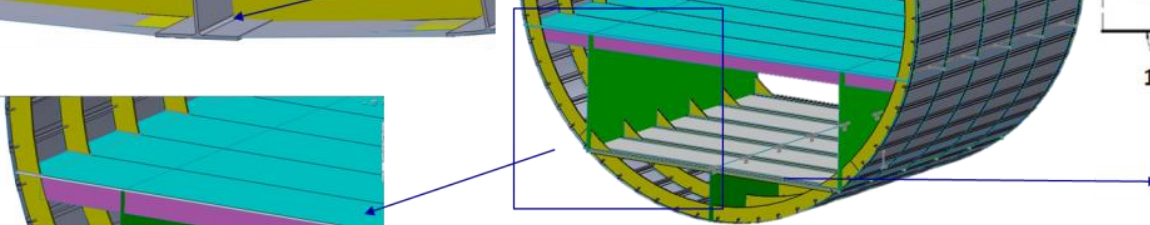

180 inch diameter cylindrical fuselage with six foamcore frames at 24 inch spacing; 60 rod-stringers at 9.4 inch spacing; stitched composite skin thickness 0.104 inch; floor, floor beam, keel beam thickness 0.204 inch, 7 keel hat frames, thickness 0.1 inch, Loads: 18.4 psi cabin pressure, 1 psi passenger floor load and 2 psi cargo load. (CFrameA)
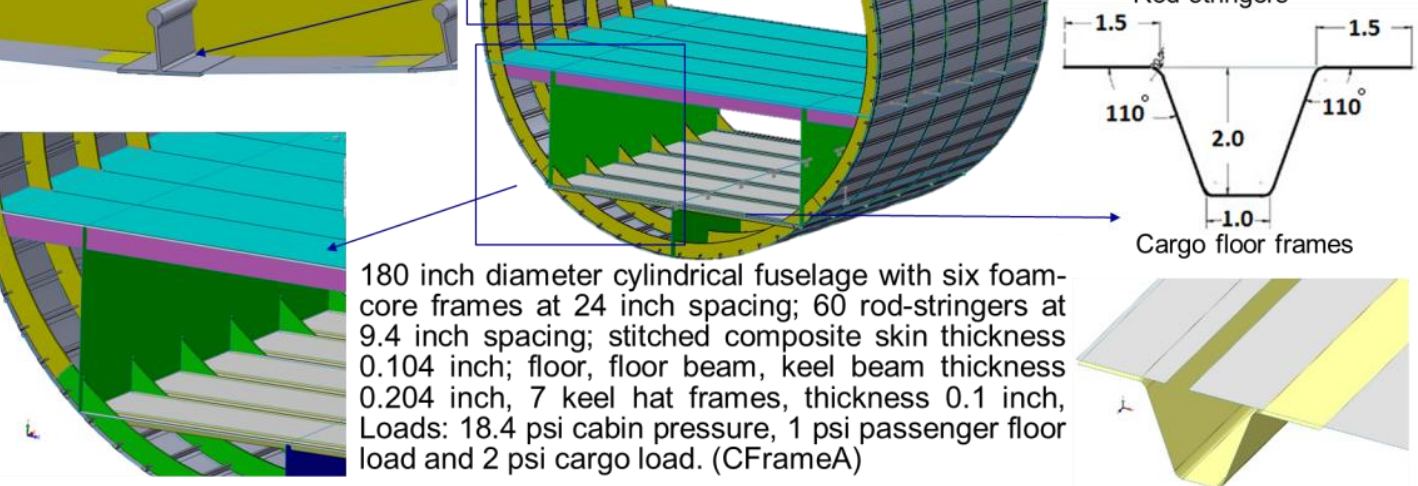

Figure 5. Cylindrical fuselage section assembly model description with curved PRESUS panel construction.

Cylindrical fuselage with pultruded rod-stringer and foam-core frame: Figure 5 shows a cylindrical fuselage assembly with curved PRSEUS panels. The 180 inch diameter fuselage section is assembled from four curved PRSEUS panels, each with six curved frames at 24 inch spacing. There are a total of 60 straight rod-stringers along the axial direction at 9.4 inch spacings. The passenger floors are stiffened with 6 inch high, 0.2 inch thick ribs. The cargo floors are stiffened with hat stiffeners and a vertical keel beam at the center. The advantages of a stiffened cylindrical fuselage are that the cabin pressure load is balanced by hoop (membrane stretching) stress which are much lower that those on the HWB fuselage. The hoop stress PR/t on the 0.1 inch outer skin is of the order $16,000 \mathrm{psi}$, with $18.4 \mathrm{psi}$ cabin over-pressure. However, the passenger and cargo floors, which are flat stiffened structure, will exhibit significantly higher stresses and deflection, even with 2 psi design cargo load. Figure 6 shows the displacement and first principal strain distribution with 18.4 psi normal cabin pressure load, 1 psi load on the passenger-floor and 2 psi load on the cargo-floor. The maximum deflection is 0.84 inch on the cargo floor with 2 psi cargo load. The maximum first principal strain 0.0053 inch/inch occurs at the junction of the floor and fuselage. The corresponding weight breakdown is shown in Table 2. Total rod-stringer weight is $233 \mathrm{lb}$. and the total frame group weight is $607 \mathrm{lbs}$. The total outer skin weight is $416 \mathrm{lbs}$. and the total passenger-floor and cargo-floor weight is 644 lbs. The total weight of this fuselage segment is $1900 \mathrm{lbs}$. The specific weight is $2.59 \mathrm{lbs}$. /square feet when divided by the 735 square feet surface area of the outer cylindrical surface, passenger-floor and cargo-floor areas. The specific weight/surface area of the cylindrical PRSEUS fuselage is very close to that for the PRSEUS multi-bay model. However, this 
part of the cylindical fuselage may also include the wing carry-through box, and possibly wheel well. The required reinforcements will significantly increase the overall structural weight.

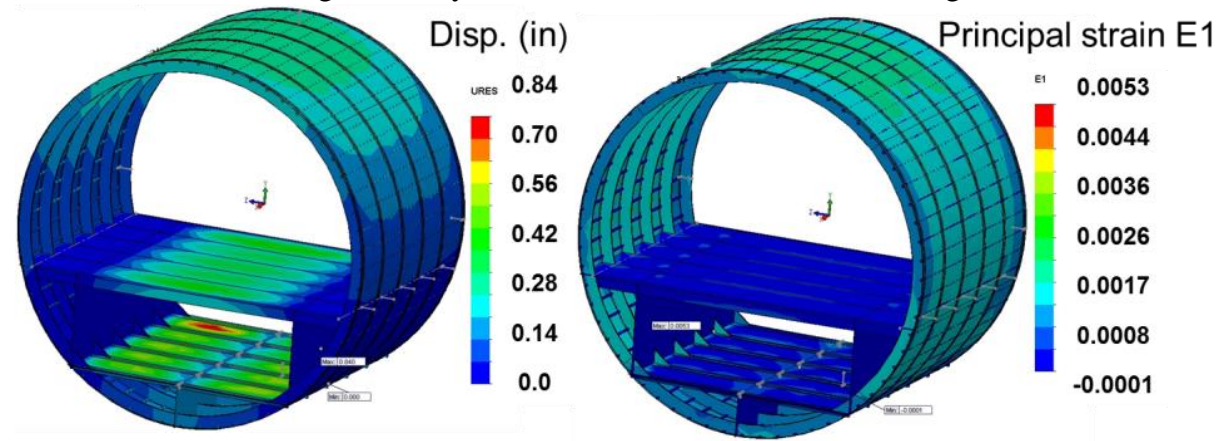

Figure 6. Cylindrical fuselage displacement and principal strain E1 with 18.4 psi cabin pressure, 1 psi load on the passenger floor and 2 psi load on the cargo floor.

Table 2. FEM structural weight breakdown of the cylindrical PRSEUS construction fuselage.

\begin{tabular}{|c|c|c|c|c|c|c|c|c|c|c|}
\hline 3. Cylindrical fuselage CFrameA & Fuselage & 90 & length $\mathrm{F}$ & 124 & frames & & stringers & & floor & 173 \\
\hline modified rod 1.65 inch b2c & rod area & web are & eflange $a$ & area & length & density & & no iten & & \\
\hline rod-stringer group (2 stack skin) & in 2 & in 2 & in 2 & in^2 & in^3 & $\mathrm{Ib} / \mathrm{in} \wedge 3$ & lbs & $\mathrm{x}$ no & & \\
\hline rod_stringer@8 in 1 wrap & 0.20 & 0.13 & 0.22 & 0.55 & 124 & 0.057 & 3.9 & 60 & 233 & 233 \\
\hline cyl Frame group @24 & length & length & area & thick & ivol & 120 and & d 200wf SI & $x$ no & & \\
\hline 4 frame core Rohacell 200 & 6 & 565 & 3393 & 0.5 & 1696 & 0.0072 & $12.2^{\prime}$ & 4 & 49 & \\
\hline frame wrap+flanges & 15.9 & 565 & 8991 & 0.1 & 935 & 0.057 & 53.3 & 6 & 320 & \\
\hline frame cover strap & 4.5 & 565 & 2545 & 0.1 & 132 & 0.057 & 7.5 & 6 & 45 & \\
\hline 2 end double frames Fib glass & 6 & 565 & 3393 & 0.5 & 1696 & 0.057 & 96.7 & 2 & 193 & 607 \\
\hline skin group & length & length & area & thick & ivol & density & wt & $x$ no it & ems & \\
\hline cyl outer skin & 124 & 565 & 70120 & 0.1 & 7293 & 0.057 & 415.7 & 1 & 416 & 416 \\
\hline floor skin & 124 & 173 & 21452 & 0.2 & 4462 & 0.057 & 254.3 & 1 & 254 & \\
\hline floor frames 6 & 6 & 173 & 1038 & 0.2 & $216^{\prime}$ & 0.057 & 12.3 & 6 & 74 & \\
\hline frame cover strap & 4.5 & 173 & 779 & 0.1 & 40 & 0.057 & 2.3 & 6 & 14 & \\
\hline floor support & 124 & 45 & 5580 & 0.1 & 580 & 0.057 & 33.1 & 2 & 66 & 408 \\
\hline keel /cargo floor & 124 & 115 & 14260 & 0.2 & 2966 & 0.057 & 169.1 & 1 & 169 & \\
\hline cargo hat stiffeners & 124 & 8.256 & 1024 & 0.1 & 106 & 0.057 & 6.1 & 6 & 36 & \\
\hline keel vertical beam & 20.8 & 124 & 2579 & 0.2 & 536 & 0.057 & 30.6 & 1 & 31 & 236 \\
\hline Total weight (lbs) & & & & & & & & lbs & 1900 & 1900 \\
\hline Loaded surface area & 105832 & in ${ }^{*}$ in & 735 & $\mathrm{ft}^{\star} \mathrm{ft}$ & & & & $\mathrm{lb} / \mathrm{sq} \mathrm{fl}$ & 2.59 & \\
\hline
\end{tabular}

Cylindrical Fuselage with stitched composite hat-stringers and foam-core frames: Figure 7 shows an alternate cylindrical fuselage concept in which the pultruded rod-stringers are replaced by stitched composite hat-stringers. This

Cylindrical fuselage with composite stitched hat-stringers at 9.4 inch spacing and foam-core frames at 24 inch spacing, Skin thickness 0.104 inch (CFrame3C)

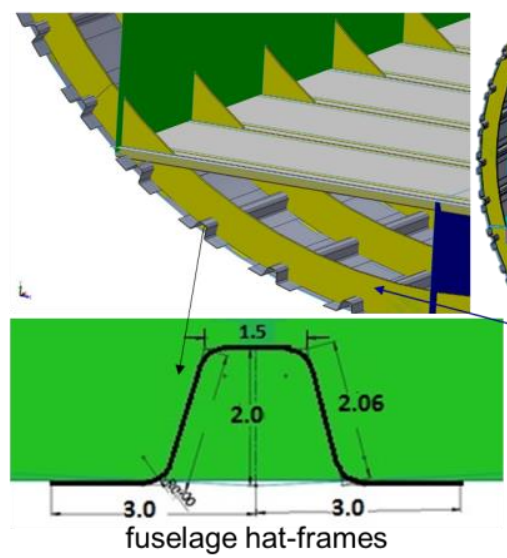

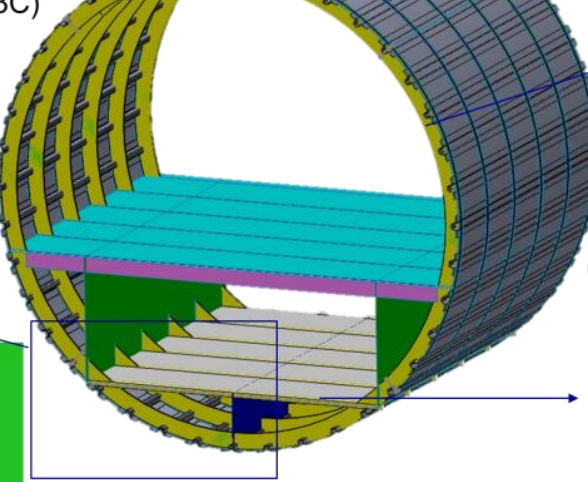

Floors, hat-stringers, hat-frames and central keel beam thickness 0.208 inch

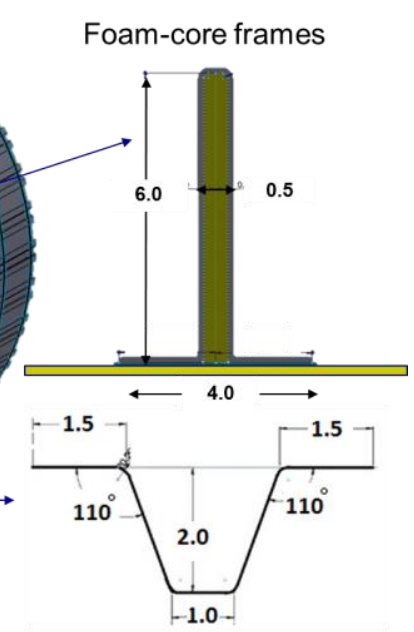

Cargo floor hat-frames

Figure 7. Cylindrical fuselage concept with foam-core frames and stitched composite hat-stringers. 
construction is similar to the B787 composite fuselage construction, and may reduce fabrication time and cost associated with the pultruded rod-stringers. Sixty hat-stringers are spaced at 9.4 inches around the fuselage rim. Passenger floors are stiffened with 0.208 inch thick, 6 inch high ribs. The cargo floors are stiffened with hat-frames and a vertical keel beam at the center.

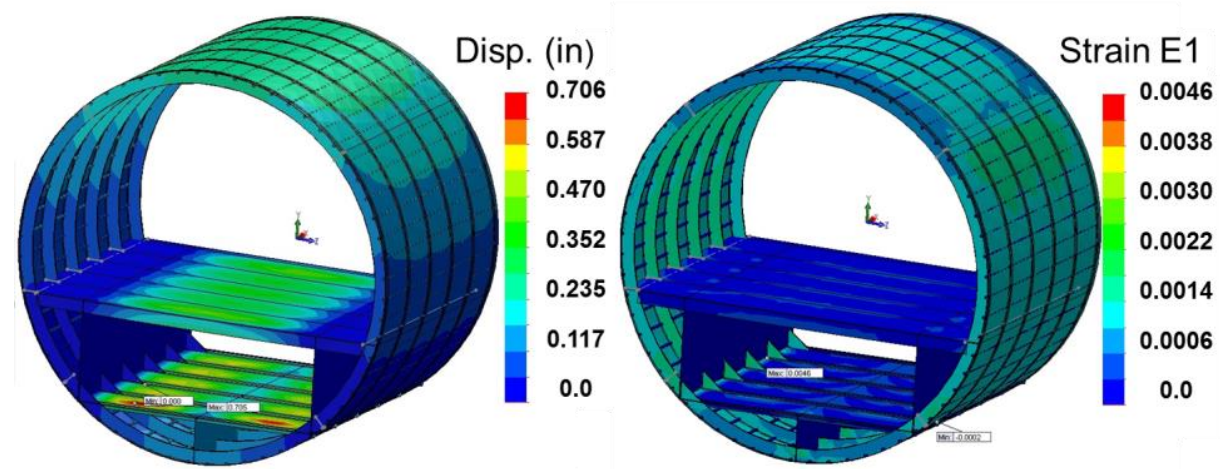

Figure 8. Displacement and first principal stress distribution with 18.4 psi internal pressure on the cylindrical fuselage with foam-core frame and stitched composite hat-stringers shown in Figure 7.

Table 3. FEM weight breakdown of cylindrical fuselage with hat-stringers and foam-core frames (90 inch radius).

\begin{tabular}{|c|c|c|c|c|c|c|c|c|c|c|}
\hline \multirow[t]{2}{*}{ 4. Cylindrical fuselage CFrame $3 \mathrm{C}$} & \multicolumn{2}{|c|}{ Fuselage 90} & \multicolumn{2}{|c|}{ length 124} & \multicolumn{2}{|c|}{ frames 6} & \multicolumn{2}{|c|}{ stringers 60} & \multirow{2}{*}{$\begin{array}{l}\text { floor } \\
\text { ms }\end{array}$} & \multirow[t]{2}{*}{173} \\
\hline & length & length & area & thickness & $\mathrm{vol}$ & density & weight & no item & & \\
\hline units & in & in & in^2 & in & in^3 & $\mathrm{Ib} / \mathrm{in}^{\wedge} 3$ & Ibs & $\mathrm{x}$ no & Ibs & \\
\hline fuselage hat stringers mod & 10.12 & 124 & 6.20 & 0.05 & 62.744 & 0.057 & 3.6 & 60 & 215 & 215 \\
\hline cyl Frame group @24 & length & length & area & thickness & $\mathrm{vol}$ & $120 / 200 v$ & wf SW & $x$ no & & \\
\hline 4 frame core Rohacell 200 & 6 & 565 & 3393 & 0.5 & 1696 & 0.0072 & 12 & 4 & 49 & \\
\hline frame wrap+flanges & 15.9 & 565 & 8991 & 0.104 & 935 & 0.057 & 53 & 6 & 320 & \\
\hline frame cover strap & 4.5 & 565 & 2545 & 0.052 & 132 & 0.057 & 8 & 6 & 45 & \\
\hline 2 end double frames Fib glass & 6 & 565 & 3393 & 0.5 & $1696^{\prime}$ & 0.057 & 97 & 2 & 193 & 607 \\
\hline skin group & length & length & area & thickness & $\mathrm{vol}$ & density & wt & $\mathrm{x}$ no ite & ems & \\
\hline cyl outer skin & 124 & 565 & 70120 & 0.104 & 7293 & 0.057 & 416 & 1 & 416 & 416 \\
\hline floor skin & 124 & 173 & 21452 & 0.208 & 4462 & 0.057 & 254 & 1 & 254 & \\
\hline floor frames 6 & 6 & 173 & 1038 & 0.208 & $216^{\prime}$ & 0.057 & 12 & 6 & 74 & \\
\hline frame cover strap & 4.5 & 173 & 779 & 0.052 & 40 & 0.057 & 2 & 6 & 14 & \\
\hline 2 vert floor support & 124 & 45 & 5580 & 0.104 & 580 & 0.057 & 33 & 2 & 66 & 408 \\
\hline keel /cargo floor & 124 & 115 & 14260 & 0.208 & 2966 & 0.057 & 169 & 1 & 169 & \\
\hline cargo hat stiffeners & 124 & 8.256 & 1024 & 0.104 & 106 & 0.057 & 6 & 6 & 36 & \\
\hline keel vertical beam & 20.8 & 124 & 2579 & 0.208 & 536 & 0.057 & 31 & 1 & 31 & 236 \\
\hline Total weight (Ibs) & & & & & & & & Ibs & 1882 & 1882 \\
\hline Loaded surface area & 105832 & in*in & 735 & $\mathrm{ft}^{*} \mathrm{ft}$ & & & & $\mathrm{lb} / \mathrm{sq} \mathrm{ft}$ & 2.56 & \\
\hline
\end{tabular}

The corresponding displacement and principal stress distributions with 18.4 psi internal cabin pressure are shown in Figure 8 . In this analysis, the fuselage skin thickness is $0.104 \mathrm{inch}$, and the passenger and cargo floor skin thicknesses are 0.208 inch. The maximum deflection is 0.7 inch on the cargo-floor and the maximum principal strain is 0.0046 at the cargo floor junction. The maximum stresses on the fuselage skin are of the order 16,000 psi. The corresponding weight breakdown of the FEM model is shown in Table 3. The weight of the 60 hat-stringers with 0.05 inch thickness is 215 lb. which is slightly lower from that of the rod-stringer (233 lbs., Table 2). The maximum stresses on the hat-stringers are about 35,000 psi, which are well under the allowable limit. Thus the rod-stringers in the PRSEUS construction shown in Figure 5 can be safely replaced by stitched composite hat-stringers with some reduction in the weight. However, the hat-stiffeners may need a foam-core to avoid local crippling.

Cylinder with inverted hat-stringers and composite C-frames: Figure 9 shows a conventional cylindrical fuselage with inverted hat-stringers replacing pultruded rod-stringers, and with composite C-frame replacing foam-core sandwich frames. This type of construction is similar to the B737 and B747 stiffened aluminum alloy fuselage, but with stitched composite material. Figure 10 shows the dispacement and first principal strain distribution with 18.4 psi internal cabin pressure. In this analysis fuselage skin thickness is 0.104 inch. The passenger-floor and cargo-floor thicknesses are 0.208 inch. This cargo floor has additional L-shaped lengthwise stringers. The maximum deflections on the flat cargo floor skin is 0.57 inches, with 2 psi cargo load. The maximum first principal strain is 0.0051 on the inverted hat-stringer which are modeled with 0.104 inch thin shell elements. The corresponding weight breakdown of the FEM model is shown in Table 4. The total FEM weight of 
the C-frames and inverted hat-stringers are lower compared to that for the PRSEUS rod-stringer and foam-core frame construction. Thus this concept is comparatively lighter that the two previous concepts shown in Figure 5 and Figure 7.

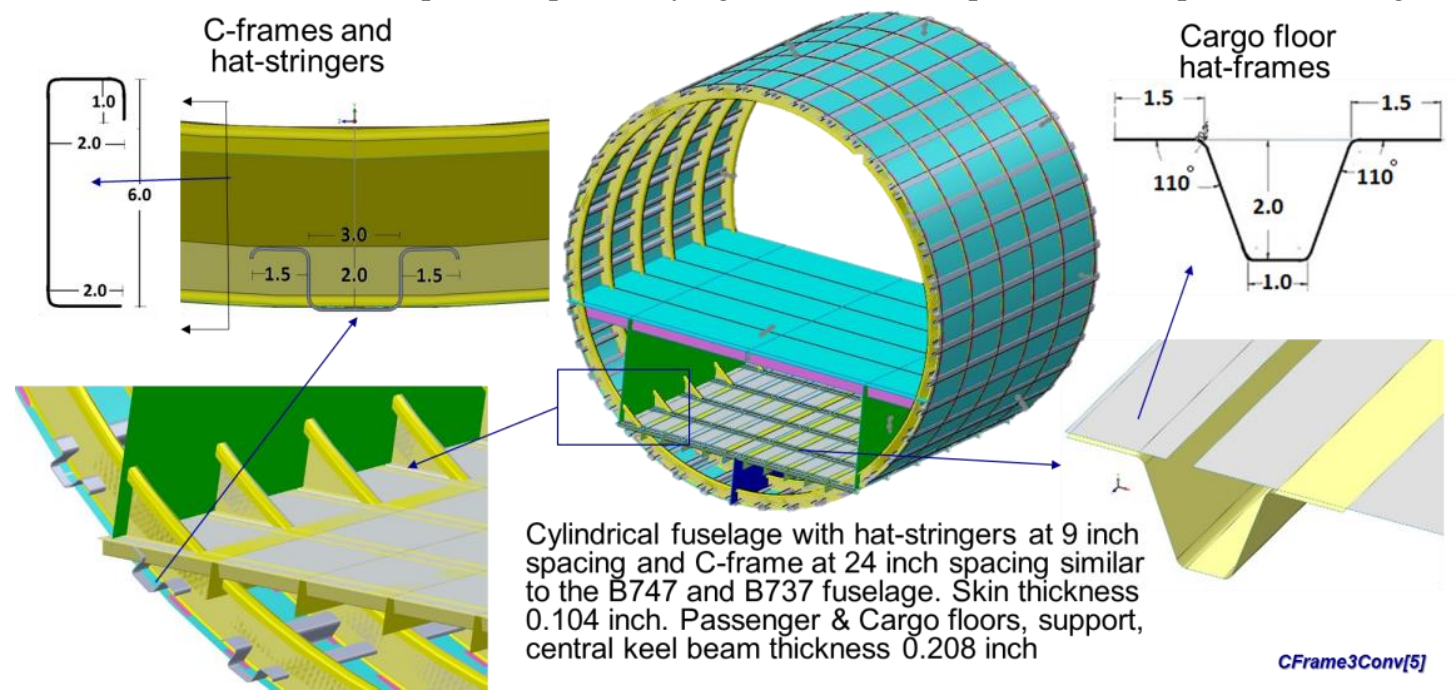

Figure 9. Cylindrical fuselage with inverted hat-stringers and C-frames similar to the B737 fuselage construction.

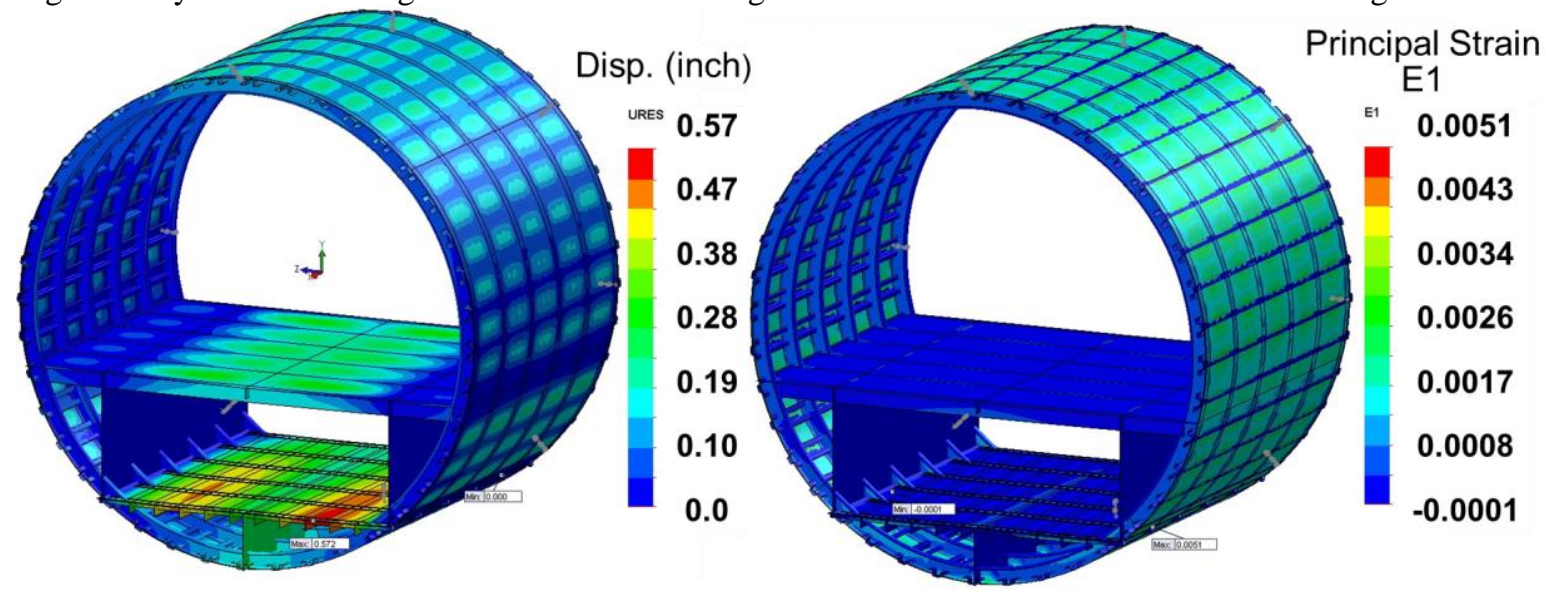

Figure 10. Displacement and first principal strain of conventional composite cylindrical fuselage with 18.4 psi cabin pressure.

Table 4. FEM weight of composite cylindrical fuselage with inverted hat-stringers and C-frames (90 inch radius).

\begin{tabular}{|c|c|c|c|c|c|c|c|c|c|c|}
\hline \multirow[t]{2}{*}{ 5. Cylindrical fuselage CFrameConv[5] } & \multicolumn{2}{|c|}{ Fuselage rad 90} & \multicolumn{2}{|c|}{ length F124 } & \multicolumn{2}{|l|}{ frames 6} & \multirow{2}{*}{$\begin{array}{l}\text { stringers } \\
\text { weight }\end{array}$} & 60 & \multirow{2}{*}{$\begin{array}{l}\text { floor } \\
\mathrm{ms}\end{array}$} & \multirow{2}{*}{\begin{tabular}{|l}
173 \\
$1 \mathrm{bs}$ \\
\end{tabular}} \\
\hline & length & length & area & thicknev & $\mathrm{vol}$ & density & & $x$ no ite & & \\
\hline units & in & in & in^2 & in & in^3 & $\mathrm{lb} / \mathrm{in}^{\wedge} 3$ & Ibs & $\mathrm{x}$ no & Ibs & \\
\hline Conv C Frame group @24 & 11 & 565 & 6220 & 0.104 & $647^{\prime}$ & 0.057 & 36.9 & 6 & 221 & 221 \\
\hline fuselage inv hat stringers & 124 & 9 & $1116^{\prime}$ & 0.104 & 116 & 0.057 & 6.6 & 60 & 397 & 397 \\
\hline fail safe strap circumferential & 5 & 565 & 2827 & 0.052 & $147^{r}$ & 0.057 & 8.4 & 6 & 50 & 50 \\
\hline fail safe strap axial & 4 & 124 & 496 & 0.050 & $25^{\prime}$ & 0.057 & 1.4 & 60 & 85 & 85 \\
\hline skin group & length & length & area & thicknev & vol & density & $w t$ & $\mathrm{x}$ no ite & & \\
\hline cyl outer skin & 124 & 565 & 70120 & 0.104 & 7293 & 0.057 & 416 & 1 & 416 & 416 \\
\hline floor skin & 124 & 173 & 21452 & 0.208 & 4462 & 0.057 & 254 & 1 & 254 & \\
\hline floor frames & 6 & 173 & 1038 & 0.208 & $216^{\top}$ & 0.057 & 12 & 4 & 49 & \\
\hline floor frame cover strap & 4.5 & 173 & 779 & 0.052 & 40 & 0.057 & 2 & 6 & 14 & \\
\hline 2 vert floor support & 124 & 45 & 5580 & 0.104 & 580 & 0.057 & 33 & 2 & 66 & 384 \\
\hline keel /cargo floor & 124 & 115 & 14260 & 0.208 & 2966 & 0.057 & 169 & 1 & 169 & \\
\hline cargo hat stiffeners & 124 & 8.26 & 1024 & 0.104 & 106 & 0.057 & 6 & 6 & 36 & \\
\hline keel vertical beam & 20.8 & 124 & 2579 & 0.208 & 536 & 0.057 & 31 & 1 & 31 & 236 \\
\hline Total weight (lbs) & & & & & & & & Ibs & 1789 & 1789 \\
\hline Loaded surface area & 105832 & in*in & 735 & $\mathrm{ft}^{*} \mathrm{ft}$ & & & & $\mathrm{Ib} / \mathrm{sq} \mathrm{ft}$ & 2.43 & \\
\hline
\end{tabular}

\section{Double-bubble Fuselage Analysis.}

Double-bubble fuselage with rod-stringer and foam-core frame: An alternative configuration for the hybrid-wing-body fuselage is a double-bubble structure with a central cabin wall as shown in Figure 11. The advantage of a double-bubble 
fuselage is that the fuselage hoop (membrane) stress resultant is balanced by the inter-cabin wall in-plane tension, since the three segments meet at 120 degrees angle. The passenger-floor and cargo-floor constructions are similar to those for the cylindrical fuselage, but without the lengthwise L-stringers. With this geometric configuration, the total fuselage width is 268.5 inch. A FEM model of this double-bubble concept was developed and preliminary results with 18.4 psi cabin pressure are also presented in Figure 11. The design passenger load of 1 psi and a cargo load of 2 psi are also applied. Detailed stress analysis results and weight analysis are presented for comparison with those of the HWB concept. The maximum deflection is 0.9 inch on the cargo-floors, and the maximum first principal strain is 0.0036 at the cabin wall and cargo floor junction, which are reinforced with triangular stringers for structural continuity and load transfer. The corresponding FEM model weight analysis is shown in Table 5. The specific weight/unit loaded area is $2.95 \mathrm{lbs}$. /sq. ft., which is considerable higher than those of the cylindrical section concepts.
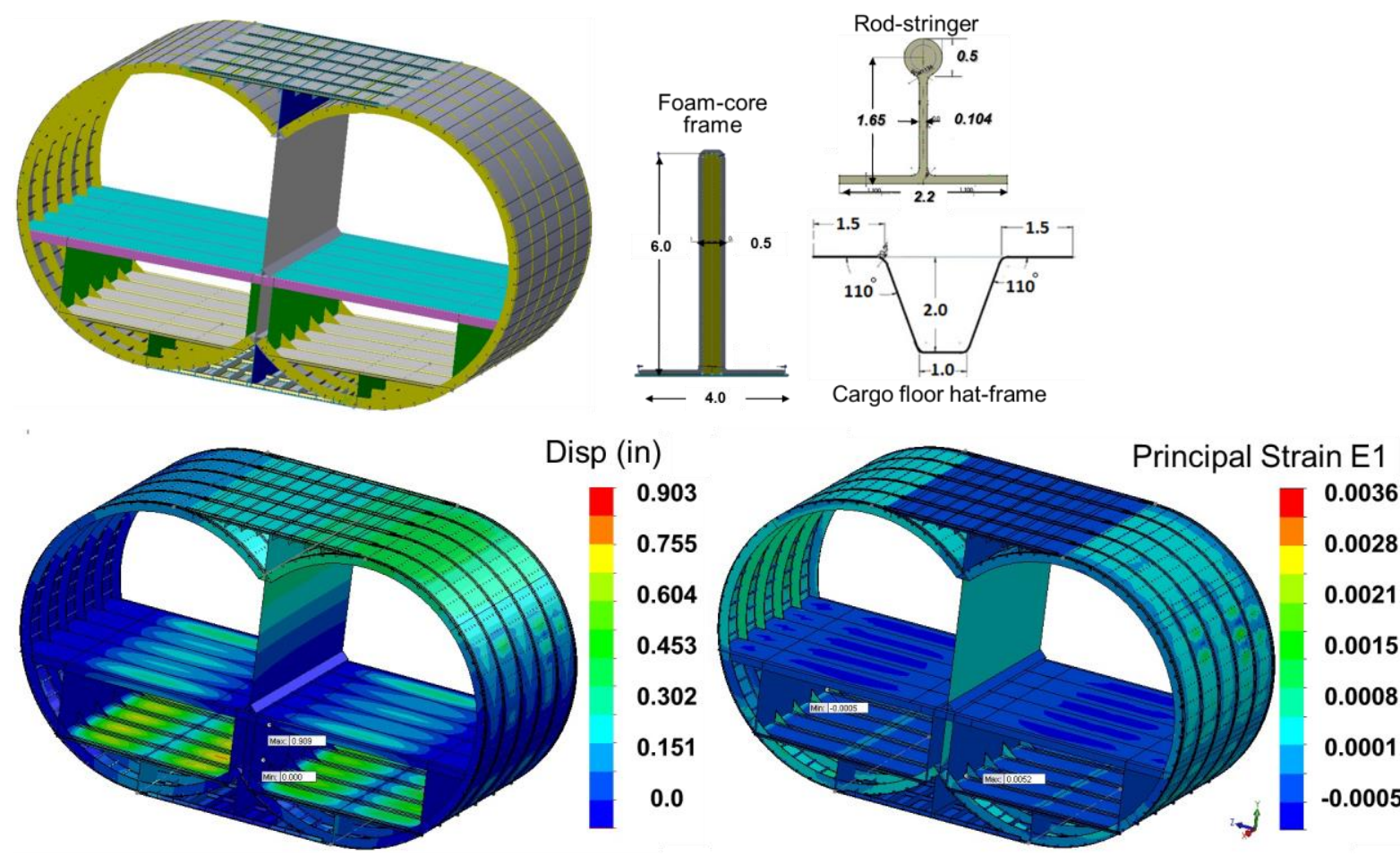

Figure 11. Analysis of PRSEUS double-bubble fuselage section model with 18.4 psi cabin pressure load.

Table 5. FEM model weight breakdown of PRSEUS double-bubble fuselage section model (90 inch radius).

\begin{tabular}{|c|c|c|c|c|c|c|c|c|c|c|}
\hline 6. DoublebubbleCFrame Fuselage $8 \mathrm{DB}[3$ & Fuselage & & length & 124 & frames 6 & & stringe & & floor & 302 \\
\hline modified rod 1.65 inch b2c & rod area & web ar & flange & area & length & density & & no item & & \\
\hline rod-stringer group ( 2 stack skin) & in^2 & $\operatorname{in}^{\wedge} 2$ & $\operatorname{in}^{\wedge} 2$ & in^2 & $i n^{\wedge} 3$ & $\mathrm{Ib} / \mathrm{in}^{\wedge} 3$ & Ibs & $\mathrm{x}$ no & & \\
\hline rod_stringer@8in 1 wrap & 0.20 & 0.13 & 0.22 & 0.55 & 124 & 0.057 & 3.9 & 80 & 311 & 311 \\
\hline cyl Frame group @24 & length & length & area & thickness & $\mathrm{vol}$ & 120 and & $200 w f S$ & $x$ no & & \\
\hline 4 frame core Rohacell 200 & 6 & 565 & 3393 & 0.5 & $1696^{\prime \prime}$ & 0.0072 & 12 & 5 & 65 & \\
\hline frame wrap+flanges & 15.9 & 565 & 8991 & 0.104 & 935 & 0.057 & 53 & 8 & 426 & \\
\hline frame cover strap & 4.5 & 565 & 2545 & 0.052 & 132 & 0.057 & 7.5 & 8 & 60 & \\
\hline 2 end double frames w Fib glass core & 6 & 565 & 3393 & 0.5 & $1696^{r}$ & 0.057 & 97 & 2.7 & 258 & 810 \\
\hline skin group & length & length & area & thickness & $\mathrm{vol}$ & density & wt & $x$ noiter & & \\
\hline cyl outer skin & 124 & 565 & 70120 & 0.104 & 7293 & 0.057 & 416 & 1.3333 & 554 & 554 \\
\hline floor skin & 124 & 302 & 37448 & 0.208 & 7789 & 0.057 & 444 & 1 & 444 & \\
\hline floor frames 6 & 6 & 302 & 1812 & 0.208 & $377^{\prime}$ & 0.057 & 21.5 & 6 & 129 & \\
\hline frame cover strap & 4.5 & 302 & 1359 & 0.052 & 71 & 0.057 & 4.0 & 6 & 24 & \\
\hline floor support & 124 & 45 & 5580 & 0.104 & 580 & 0.057 & 33 & 4 & 132 & 729 \\
\hline keel/cargo floor & 124 & 230 & 28520 & 0.208 & 5932 & 0.057 & 338 & 2 & 676 & \\
\hline cargo hat stiffeners & 124 & 8.3 & 1024 & 0.104 & 106 & 0.057 & 6.1 & 12 & 73 & \\
\hline keel vertical beam & 21 & 124 & 2579 & 0.208 & 536 & 0.057 & 30.6 & 2 & 61 & 810 \\
\hline intercabin wall & 124 & 128 & 15872 & 0.208 & 3301 & 0.057 & 188 & 1 & 188 & 188 \\
\hline inter cabin wall joints & 124 & 16.4 & 2029 & 0.208 & 422 & 0.057 & 24.1 & 6 & 144 & 144 \\
\hline upper suface and vertical wall & 124 & 153 & 19007 & 0.052 & 988 & 0.057 & 56 & 1 & 56 & \\
\hline Upper+lower Lstiffeners & 127 & 6 & $764 "$ & 0.052 & 40 & 0.057 & 2.26 & 10 & 23 & \\
\hline Upper+lower hat stiffeners & 124 & 8.3 & 1024 & 0.052 & 53 & 0.057 & 3.0 & 12 & 36 & \\
\hline lower surface and vertical wall & 124 & 153 & 19007 & 0.052 & 988 & 0.057 & 56.3 & 1 & 56 & 172 \\
\hline Total weight (lbs) & & & & & & & & Ibs & 3719 & 3719 \\
\hline Loaded surface area w/o incab wall & 181451 & in*in & 1260 & $\mathrm{ft}^{*} \mathrm{ft}$ & & & & $\mathrm{Ib} / \mathrm{sq} \mathrm{ft}$ & 2.95 & \\
\hline
\end{tabular}


Conventional Aluminum Cylindrical Fuselage: A conventional cylindrical fuselage model similar to the Boeing 737 construction $^{21}$ with 7075-T6 aluminum fuselage was developed and analyzed with 18.4 psi over-pressure condition. The construction is same as that shown in Figure 9. All the outer skins, fail-safe frame cover straps, C-frames and inverted hatstringer thicknesses are assumed to be 0.06 inches which is typical for this size fuselage ${ }^{21}$. The hoop stress is about 28,000 psi. The passenger floor thickness is 0.208 inch. Floor frames, cargo floor skin, hat-frames and L-stringers are all made of 0.104 inch thin aluminum extrusions. The component thicknesses and FEM weight breakdown are shown in Table 6. The structural deflection and von-Mises stress distributions are shown in Figure 12. The deflections, stress and strain distributions of the aluminum alloy cylindrical fuselage section are similar to those shown in Figure 10 with composite construction.

Figure 12. Conventional aluminum fuselage displacement and von-Mises stress distribution at 18.4 psi cabin pressure.
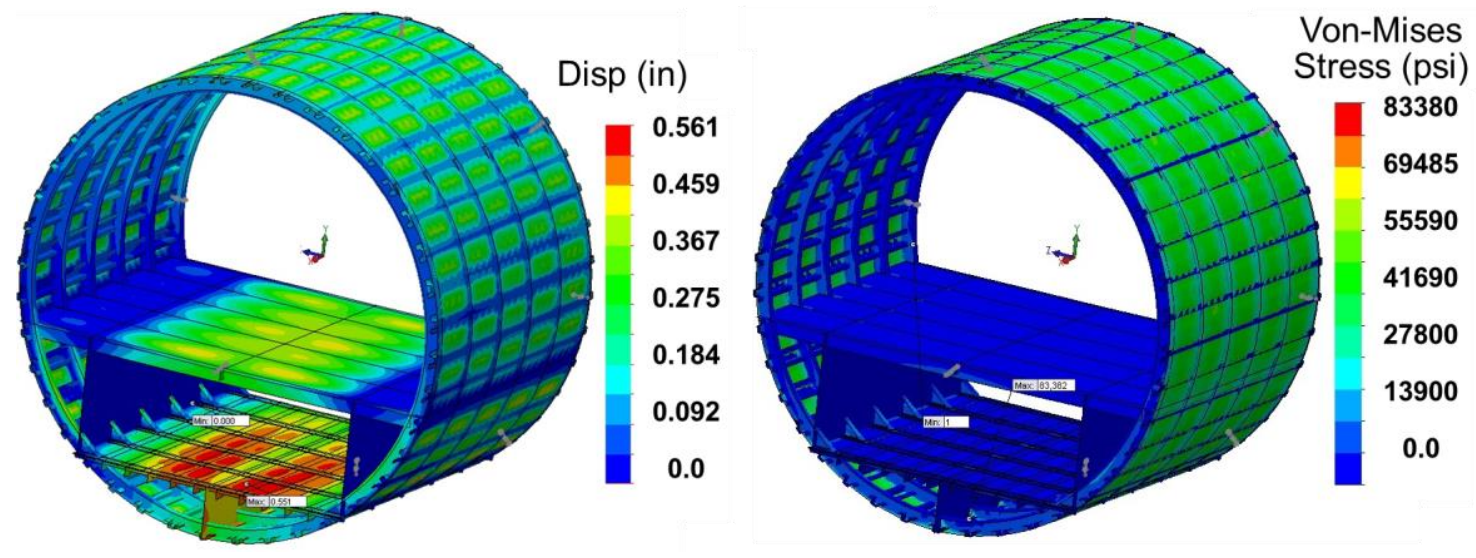

Table 6. FEM model weight breakdown of the aluminum 7075-T6 baseline cylindrical fuselage.

\begin{tabular}{|c|c|c|c|c|c|c|c|c|c|c|}
\hline \multirow{3}{*}{$\begin{array}{l}\text { 7. Cylindrical fuselage CFrameConv[6] } \\
\text { AL 7075-T6 } \\
\text { units }\end{array}$} & Fuselage & \multicolumn{2}{|c|}{90 length } & 124 & \multicolumn{3}{|c|}{6 stringe } & \multicolumn{2}{|c|}{60 floor } & 173 \\
\hline & length & length & area & thickness & $\mathrm{vol}$ & density & weight & $x$ no ite & ems & Ibs \\
\hline & in & in & in^2 & in & in^3 & $\mathrm{lb} / \mathrm{in}^{\wedge} 3$ & Ibs & $x$ no & Ibs & \\
\hline Conv C Frame group @24 & 11 & 565 & 6220 & 0.06 & 373 & 0.101 & 37.7 & 6 & 226 & 226 \\
\hline fuselage inv hat stringers & 124 & 9 & 1116 & 0.06 & 67 & 0.101 & 6.8 & 60 & 406 & 406 \\
\hline fail safe strap circumferential & 5 & 565 & 2827 & 0.05 & 141 & 0.101 & 14.3 & 6 & 86 & 86 \\
\hline fail safe strap axial & 4 & 124 & 496 & 0.06 & 30 & 0.101 & 3.0 & 60 & 180 & 180 \\
\hline skin group & length & length & area & thickness & vol & density & wt & $x$ no ite & ems & \\
\hline cyl outer skin & 124 & 565 & 70120 & 0.06 & 4207 & 0.101 & 424.9 & 1 & 425 & 425 \\
\hline floor skin & 124 & 173 & 21452 & 0.208 & 4462 & 0.101 & 450.7 & 1 & 451 & \\
\hline floor frames & 6 & 173 & 1038 & 0.1 & 104 & 0.101 & 10.5 & 4 & 42 & \\
\hline floor frame cover strap & 4.5 & 173 & 779 & 0.104 & 81 & 0.101 & 8.2 & 6 & 49 & \\
\hline 2 vert floor support & 124 & 45 & 5580 & 0.104 & 580 & 0.101 & 58.6 & 2 & 117 & 659 \\
\hline keel /cargo floor & 124 & 115 & 14260 & 0.104 & 1483 & 0.101 & 149.8 & 1 & 150 & \\
\hline cargo hat stiffeners & 124 & 8.26 & 1024 & 0.06 & 61 & 0.101 & 6.2 & 6 & 37 & \\
\hline keel vertical beam & 20.8 & 124 & 2579 & 0.1 & 258 & 0.101 & 26.0 & 1 & 26 & 213 \\
\hline Total weight (Ibs) & & & & & & & & Ibs & 2195 & 2195 \\
\hline Loaded surface area & 105832 & in*in & 73 & $\mathrm{t}^{*} \mathrm{ft}$ & & & & $\mathrm{Ib} / \mathrm{sq} \mathrm{ft}$ & 2.99 & \\
\hline
\end{tabular}

\section{V.Structural Model Weight Comparison}

Table 7 shows FEM weight of each of the seven concepts analyzed in this paper. Although the multi-bay, cylindrical doublebubble section fuselage concepts are different in size and construction architecture, a relative structural weight comparison can be established by normalizing the computed weight with the total pressurized surface area, passenger-floor and cargofloor area. The last two columns in Table 7 show the normalizing surface area and corresponding specific weights, and is plotted as a bar chart in Figure 13. The FEM structural specific weight per unit loaded surface area varies from $2.57 \mathrm{lbs}$. /sq. feet for the multi-bay and bulkhead, to $2.95 \mathrm{lbs}$. /sq. feet for the double-bubble fuselage. With PRSEUS construction, the HWB fuselage section specific weight of $2.57 \mathrm{lbs}$. /sq. ft. is slightly higher than $2.43 \mathrm{lbs}$. /sq. ft. for PRSEUS cylindrical fuselage, although the maximum stress level on the outer skin are lower in the cylindrical case. It may be noted that if the rod-stringers and sandwich foam-core frames are replace by hat-stringers and C-frames (Figure 9) the specific weight is reduced to $2.43 \mathrm{lbs}$. /sq. ft. Comparing the cases 3, 4 and 5, it may be possible to replace the foam-core frames and pultruded rod-stringers with hat-stringers and $\mathrm{C}$-frames in order to save weight and reduce construction complexity. The double-bubble PRSEUS construction have a specific weight of $2.95 \mathrm{lbs}$. /sq. $\mathrm{ft}$., which is heavier than all other concepts. This is due to the additional aerodynamic surface panel weights above and below the inter-bubble joints. It is also interesting to note that the conventional aluminum fuselage specific weight is $2.99 \mathrm{lbs}$. /sq. ft. which is about $13 \%$ higher than the PRSEUS Multi-bay 
and the PRSEUS cylindrical fuselage specific weights (2.57 lbs. /sq. ft. and $2.59 \mathrm{lbs}$. /sq. ft., respectively). Thus the present structural system analysis indicates that the PRSEUS HWB multi-bay fuselage can be structurally as efficient as the conventional composite cylindrical fuselage and superior that the conventional aluminum alloy construction.

Table 7. Structural model weight comparison of multi-bay, bulkhead, cylindrical and double-bubble fuselage concepts.

\begin{tabular}{|c|c|c|c|c|c|c|}
\hline \multicolumn{3}{|l|}{ Analysis Model Description } & \multirow{2}{*}{\multicolumn{2}{|c|}{$\begin{array}{l}\text { weight } \\
\text { lbs }\end{array}$}} & \multirow{2}{*}{$\begin{array}{l}\text { area } \\
\mathrm{ft}^{\wedge} 2\end{array}$} & \multirow{2}{*}{$\frac{\mathrm{wt} / \text { area }}{\mathrm{Ib} / \mathrm{ft}^{\wedge} \mathrm{2}}$} \\
\hline & & units & & & & \\
\hline 1. BAY6A 2 stack skin $2 / 1$ stack wrap rod & $s @ 6+8,2+2$ fra & nes at 24 & $\overline{1}$ & 2320 & 902 & 2.57 \\
\hline 2. Bulkhead1b/4 (2 stack skin, 2 stack w & ap, 8 inch rods & pacing, Hor frame) & 2 & 818 & 350 & 2.34 \\
\hline 3. Cylindrical fuselage CFrameA & PRSEUS & Frame & 3 & 1900 & 735 & 2.59 \\
\hline 4. Cylindrical fuselage CFrame3C & Hat-stringer & Frame & 4 & 1882 & 735 & 2.56 \\
\hline 5. Cylindrical fuselage CFrameConv[5] & IHat-stringer $\mathrm{C}$ & -Frame comp & 5 & 1789 & 735 & 2.43 \\
\hline 6. DoublebubbleCFrame Fuselage8DB[3 & ]PRSEUS & Frame & 6 & 3719 & 1260 & 2.5 \\
\hline 7. Cylindrical fuselage CFrameConv[6] & IHat-stringer $\mathrm{C}$ & -frame Aluminum & 7 & 2195 & 735 & 2.99 \\
\hline
\end{tabular}

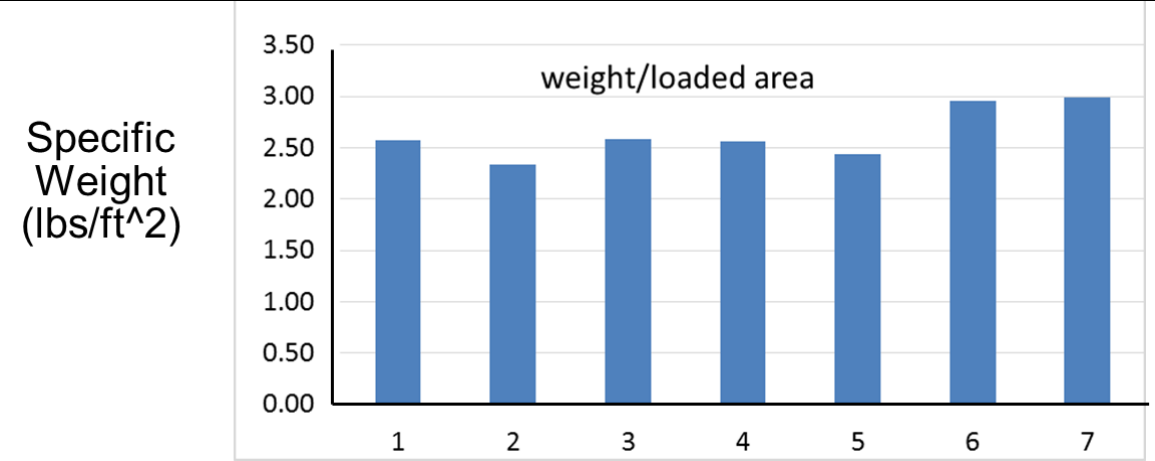

Figure 13. Relative conceptual FEM configuration weights per unit loaded surface area for PRSEUS concepts and stiffener alternatives: 1. Multi-bay; 2. Bulkhead; 3. Cylindrical PRSEUS 4. Cylindrical with hat-stringers; 5. Cylindrical with inverted hat-stringers and C-Frames; 6. PRSEUS Double-bubble, 7. Conventional aluminum cylindrical fuselage with inverted hatstringers and C-Frames.

\section{Extended Vehicle Model}

Figure 14 shows preliminary finite element assembly model of an extended multi-bay, rear bulkhead and inter-bay joints along with outer wing extensions. All frames are modeled as 6 inch deep ribs. For initial trial result, the skins and frames are assumed to have 0.5 inch thickness. However, in these simplified model, the PRSEUS rod-stringers or hat-stringers are replaced by equivalent smeared thickness, that provide same stiffness for a given stiffener spacing. The computation of equivalent skin thickness that provide same plate bending stiffness for a given rod-stiffener geometry and spacing is explained next.
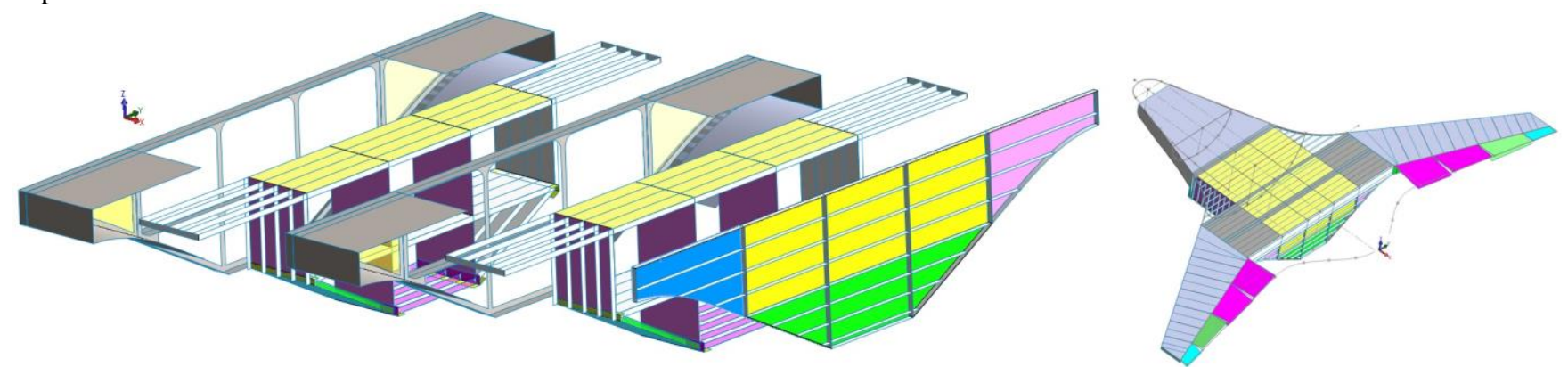

Figure 12. Extended multi-bay, bulkhead and inter-bay joint model exploded view, and vehicle assembly.

Equivalent thickness computation for flat plate bending: For an isotropic thin rectangular plate of uniform equivalent thickness $T_{e q}$, length $L$ and width B, the maximum deflection may be expressed by Eq. 1 which is a function of the pressure load q, plate bending stiffness $D$ and the factor $k$ that is calculated from analytical solution for each boundary condition. The factor $k$ can be presented in tabular form ${ }^{18-19}$, as a function of the ratio $\mathrm{B} / \mathrm{L}$. For example, for a square plate with built-in edges, $k=0.00126$ for $B / L=1$. For a simply supported isotropic square plate, $k=0.00406$. 


$$
w_{\max }=k . q . L^{4} / D \text { where } D=E . T_{e q}{ }^{3} / 12\left(1-v^{2}\right)
$$

From ideal orthotropic plate theory ${ }^{18}$, for a simply supported stiffened rectangular plate of thickness $t$, a good closed form maximum deflection is given by

$$
w_{\max }=\frac{16 q}{\pi^{6}} \frac{1}{\left(\frac{D_{x}}{L^{4}}+\frac{2 H}{L^{2} B^{2}}+\frac{D_{y}}{B^{4}}\right)}
$$

The flexural rigidity $\mathrm{D}_{\mathrm{x}}, \mathrm{D}_{\mathrm{y}}$ and $\mathrm{H}$ can be approximately defined by the Eqs. (3-5).

$$
\begin{aligned}
& D_{x}=\frac{E_{x} t^{3}}{12\left(1-v_{x} v_{y}\right)}+\frac{E_{x} t Z_{o x}{ }^{2}}{12\left(1-v_{x} v_{y}\right)}+\frac{E_{x}^{\prime} I_{x}}{b} \\
& D_{y}=\frac{E_{y} t^{3}}{12\left(1-v_{x} v_{y}\right)}+\frac{E_{y} t Z_{o y}{ }^{2}}{12\left(1-v_{x} v_{y}\right)}+\frac{E_{y}^{\prime} I_{y}}{a} \\
& H=\sqrt{D_{x} D_{y}}
\end{aligned}
$$

For an orthotropic bi-axially stiffened plate, $D / L^{4}$ in Eq. (1) is replaced by $\left[D_{x} / L^{4}+2 H /\left(L^{2} B^{2}\right)+D_{y} / B^{4}\right] / 4$ with k factors for the specific $B / L$ ratio $(L<B)$ from Ref. 18. This approximation, shown in Eq. (6) is applied to bi-axially stiffened orthotropic plate.

$$
w_{\max }=\frac{4 k q}{\left(\frac{D_{x}}{L^{4}}+\frac{2 H}{L^{2} B^{2}}+\frac{D_{y}}{B^{4}}\right)}
$$

For simplification of a full vehicle model development with PRSEUS construction, the foam-core frames may be replaced by beam elements with same wrap thickness. However, it may be necessary to use equivalent shell thickness that provides the

\begin{tabular}{|c|c|c|c|c|c|}
\hline \multirow{2}{*}{$\begin{array}{l}\text { Component } \\
\text { Composite }\end{array}$} & \multirow{2}{*}{\begin{tabular}{|l|} 
symbol \\
Ex \\
\end{tabular}} & \multirow{2}{*}{\begin{tabular}{|l|} 
property \\
Elastic modulus \\
\end{tabular}} & \multicolumn{2}{|c|}{ direction value } & \multirow{2}{*}{$\begin{array}{l}\text { unit } \\
\text { psi }\end{array}$} \\
\hline & & & $x$ & $9.75 \mathrm{E}+06$ & \\
\hline Skin cover and & Ey & Elastic modulus & y & $4.86 E+06$ & psi \\
\hline \multirow[t]{9}{*}{ frame wrap } & Gxy & Shear modulus & & 2.27E+06 & psi \\
\hline & nux & Poisson's ratio & & 0.39 & \\
\hline & nuy & Poisson's ratio & & 0.2 & \\
\hline & rho & density & & 0.057 & $\mathrm{lb} / \mathrm{in}^{\wedge} 3$ \\
\hline & Ftx & allowable stress $\mathrm{x}$ & tension & 105100 & psi \\
\hline & Fty & allowable stress y & tension & 79200 & psi \\
\hline & Fcx & allowable stress $\mathrm{x}$ & comp & 46500 & psi \\
\hline & Fcy & allowable stress y & comp & 37900 & psi \\
\hline & Fs & allowable stress & shear & 30000 & psi \\
\hline \multirow[t]{2}{*}{ rod-stringer } & E'y & Elastic modulus & & $1.90 \mathrm{E}+07$ & psi \\
\hline & ny & Poisson's ratio & & 0.29 & \\
\hline WF110 core & $\mathbf{E}$ & Elastic modulus & & 21000 & psi \\
\hline \multirow[t]{2}{*}{ Rohacell } & G & Shear modulus & & 8250 & \\
\hline & rho & density & & 0.0036 & $\mathrm{lb} / \mathrm{in}^{\wedge} 3$ \\
\hline \multirow[t]{3}{*}{ WF220 core } & $\mathbf{E}$ & Elastic modulus & Rohacell & 39150 & psi \\
\hline & $\mathbf{G}$ & Shear modulus & & 14500 & psi \\
\hline & rho & density & & 0.0074 & lb/in^3 \\
\hline
\end{tabular}
same bending stiffness of shells with rod-stringer. Thus by equating D and Dy from Eq. (1) and (4) one can write the equivalent thickness as

$$
T_{e q}=\left[D_{y} * 12\left(1-v^{2}\right) / E y\right]^{1 / 3}
$$

Table 8. Composite material properties and allowable stresses.

Table 8 shows the general material properties for the FEM analysis and the analytical orthotropic plate analysis. In order to develop the FEM model of the full vehicle with PRSEUS construction, it was necessary to compute the equivalent thickness of the PRSEUS panel with the rod-stringer and their spacing. If the rod-stringers are 1.4 inch base to center to height and 6 inch spacing, the equivalent thickness is 1.18 inch. If the frames at 20 inch spacing are also smeared into the single-stack 0.052 inch skin, the equivalent thickness is 1.76 inch. Considering that the frames are modeled appropriately, for the rod-stringer configuration with 1.65 inch base to center to height and at 6 inch spacing as shown in Figure 2, the equivalent thickness is 1.33 inch. With two stack skin and 8 inch rodstringer spacing, the equivalent smeared thickness is $1.25 \mathrm{inch}$. The detail stiffness properties and equivalent thickness values for one and two stack skin and rod-stiffener at 6 and 8 inch spacing are shown in Table 8. Figure 15 shows initial deformation with 18.4 internal cabin pressure.

Table 9. Equivalent skin thickness computation for one or two stack skin, and rod-stiffeners with 6 or 8 inch spacing. 


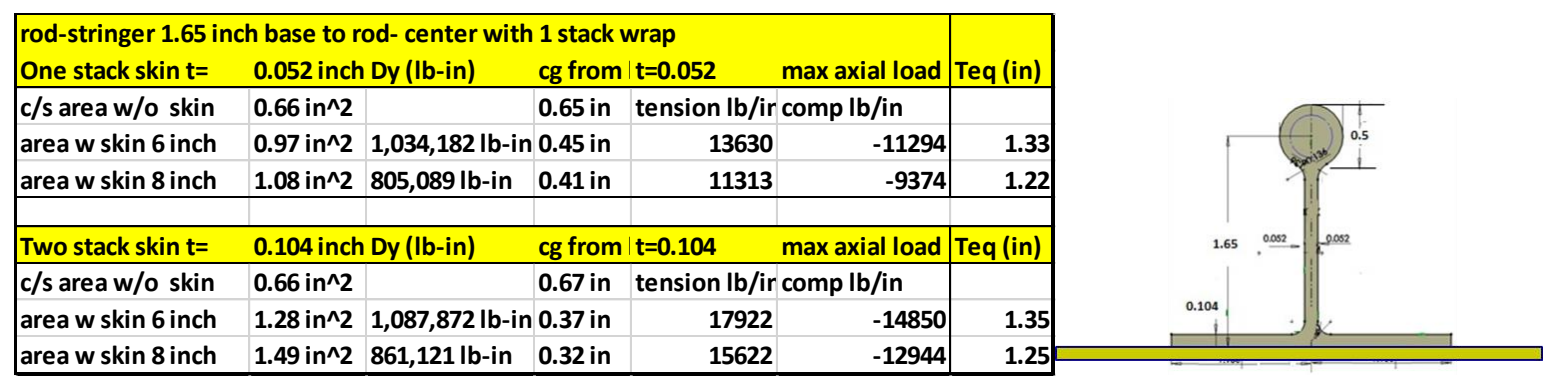

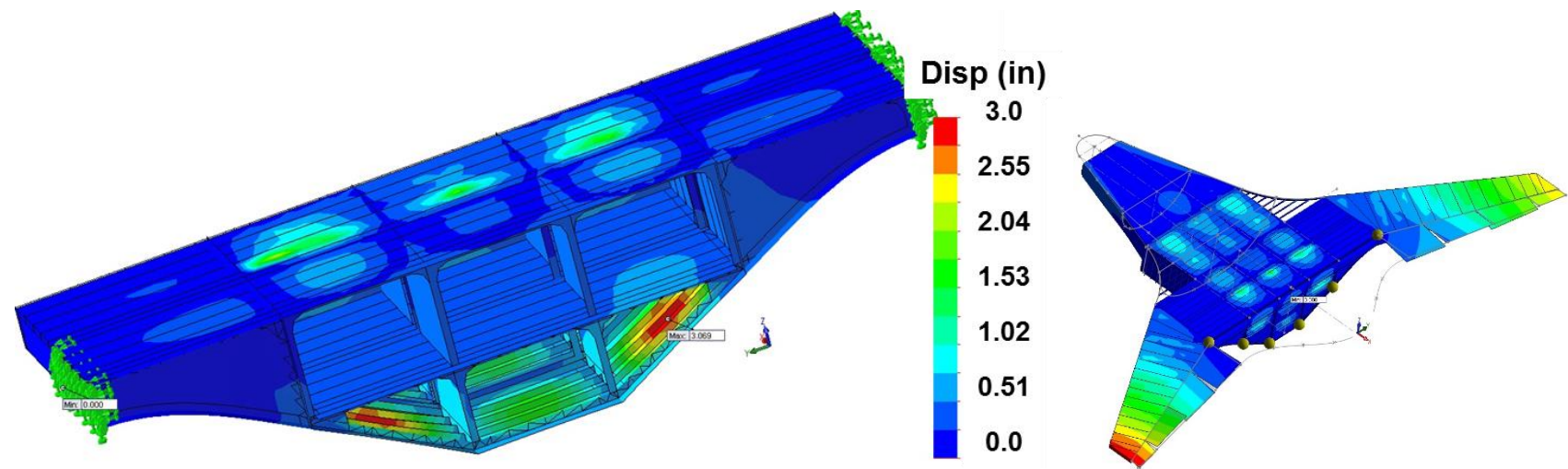

Figure 15. Extended vehicle model assembly deformation with 0.5 inch skin and frames with 18.4 psi cabin pressure load.

\section{Conclusions}

Based on lessons learned from previous Hybrid-Wing-Body (HWB) structural design studies, high fidelity finite-element models (FEM) have been developed to evaluate the performance benefits of the Pultruded Rod Stitched Efficient Unitized Structure (PRSEUS) construction. In order to assess the comparative weight/strength benefits, PRSEUS composite FEM models of a cylindrical fuselage and a double-bubble section concept have also been developed. Stress analysis and scenario based case studies at the 18.4 psi over-pressure load condition were conducted for design improvement. Several alternative construction concepts with hat-stringers and C-frames were also developed and analysed for the cylindrical section fuselage. This type of frame-stringer construction will reduce the weight and fabrication complexity associated with the foam-core sandwich frame and pultruded rod-stringer constuction. The FEM structural analysis results and component weights were presented for relative performance benefit assessments. The HWB model specific-weight values per unit loaded surface were compared to that of the composite cylindrical and the double-bubble section fuselage concepts. The structural stress analysis and specific weight comparison of these stitched-composite advanced aircraft fuselage section concepts demonstrated that the pressurized HWB fuselage section assembly can be structurally as efficient as the conventional cylindrical fuselage section with PRSEUS and composite stringer-frame construction, and significantly better than the conventional aluminum construction. The specific weight of the HWB section is $14 \%$ lower than the conventional cylindrical aluminum fuselage, and 13\% lower than the double-bubble PRSEUS construction. However, the maximum stress and strain levels of the HWB fuselage at the 18.4 psi over-pressure condition are generally higher than those for the cylindrical fuselage. Also, the adverse aerodynamic effect due the deformation (or pillowing) of the HWB outer-surface at operational cabin pressure need to be investigated.

\section{Acknowledgments}

This research was sponsored by the NASA Environmentally Responsible Aviation (ERA) Project in collboration with the NASA Langley Research Directorate, and the Boeing Company, Huntington Beach. The author wishes to thank Dr. Fayette Collier, Project Manager, ERA Project; Pamela Davis, Assoc. Project Manager, Airframe Technology; William Kimmel, Chief Technologist, Systems Analysis and Concepts Directorate; Daniel Williams, Branch Head, and Philip Arcara, Assistant Branch Head, Aeronautical Systems Analysis Branch; as well as the Aeronautics Research Mission Directorate for funding this research. Technical discussion and guidance from Dr. Frank Gern, Alex Velicki, Dawn Jegley, Andrew Lovejoy, Craig Nickol, Andy Hahn, Trevor Laughlin, and Jason Corman are greatly appreciated. 


\section{References}

${ }^{1}$ Liebeck, R. H., Page, M. A., and Rawdon, B. K., "Blended-Wing-Body Subsonic Commercial Transport," AIAA 19980438, January 1998.

${ }^{2}$ Mukhopadhyay, V., "Structural Concepts Study of Non-circular Fuselage Configurations," Paper No. AIAA SAE WAC-67, World Aviation Congress, Los Angeles, Calif. Oct. 22-24, 1996.

${ }^{3}$ Liebeck, R. H, "Design of the Blended Wing Body Subsonic Transport," Journal of Aircraft, Vol. 41, No. 1, Jan-Feb. 2004, pp. 10-25.

${ }^{4}$ Hoffman, K., "Air Vehicle Technology Integration Program (AVTIP), Multi-role Bomber Structural Analysis, AFRL-VAWP-TR-2006-3067, May 2006, Final Report for 14 December 2004-May 2006, AFRL-VA-WP-TR-2006-3067.

${ }^{5}$ Mukhopadhyay, V., Sobieszczanski-Sobieski, J., Kosaka, I., Quinn, G., and Vanderplaats, G., "Analysis, Design and Optimization of Non-cylindrical Fuselage for Blended-Wing-Body Vehicle," Journal of Aircraft, Vol. 41, No. 4, JulyAugust, 2004, pp. 925-930.

${ }^{6}$ Velicki, A., and Thrash, P. J., "Advanced Structural Concept Development Using Stitched Composites," The Boeing Company, Huntington Beach, California 92647-2099, AIAA Paper 2008-2329.

${ }^{7}$ Velicki, A., Thrash, P. J., and Jegley, D., "Airframe Development for the Hybrid Wing Body Aircraft," AIAA Paper 2009932.

${ }^{8}$ Velicki, A., Yovanof, N., Baraja, J., Linton, K., Li, V., Hawley, A., Thrash, P., DeCoux, S., and Pickell, R., "Damage Arresting Composites for Shaped Vehicles-Phase II Final Report, NASA/CR 2011-216880, 2011.

9 Lovejoy, A. E., Rouse, M., Linton, K. A., and Li, V. P., "Pressure Testing of a Minimum Gauge PRSEUS Panel," AIAA2011-1813, 52nd AIAA/ASME/ASCE/AHS/ASC Structures, Structural Dynamics, and Materials Conference, Denver, April, 2011.

10 Bergan, A., Bakuckas, J., Jr., Lovejoy, A., Jegley, D., Linton, K., Korkosz, G., Awerbuch, J., and Tan, T-M., "Full-Scale Test and Analysis of a PRSEUS Fuselage Panel to Assess Damage-Containment Features," 2011 Airworthiness \& Sustainment Conference, San Diego, California, April 18-21, 2011.

${ }^{11} \mathrm{Wu}, \mathrm{H}$. , and Shaw, P., "Analysis of a Hybrid Wing Body Center Section Test Article", AIAA Paper 2013-1734: 54th AIAA/ASME/ASCE/AHS/ASC Structures, Structural Dynamics, and Materials Conference, Boston, April 2013.

${ }^{12}$ Mukhopadhyay, V: "Hybrid Wing-Body Pressurized Fuselage Modeling, Analysis, and Design for Weight Reduction," AIAA Paper 2012-1999, 53rd AIAA/ASME/ASCE/AHS/ASC Structures, Structural Dynamics, and Materials Conference, Honolulu, April 2012.

${ }^{13}$ Mukhopadhyay, V: "Hybrid Wing-Body Pressurized Fuselage and Bulkhead Design and Optimization," AIAA Paper 20131717, 54th AIAA/ASME/ASCE/AHS/ASC Structures, Structural Dynamics, and Materials Conference, Boston, April 2013.

${ }^{14}$ Gern, F. H., "Finite Element Based HWB Center body Structural Optimization and Weight Prediction, AIAA Paper 20121606, April 2012.

${ }^{15}$ Gern, F., "Conceptual Design and Structural Analysis of an Open Rotor Hybrid Wing Body Aircraft," AIAA Paper 20131688: 54th AIAA/ASME/ASCE/AHS/ASC Structures, Structural Dynamics, and Materials Conference, Boston, April 2013.

${ }^{16}$ Przekop, A., Wu, H. T., Shaw, P., "Nonlinear Finite Element Analysis of a Composite Non-Cylindrical Pressurized Aircraft Fuselage Structure," AIAA-2014-1064, 55th AIAA/ASME/ASCE/AHS/ASC Structures, Structural Dynamics, and Materials Conference, National Harbor, MD, January 2014.

${ }^{17}$ Mukhopadhyay, V: "Hybrid-Wing-Body Vehicle Composite Fuselage Analysis and Case Study," AIAA 2014-2427, AIAA AVIATION 2014 Conference, Atlanta, June 2014.

${ }^{18}$ Timoshenko, S., and Krieger, S.W., "Theory of Plates and Shells," McGraw-Hill, New York, $2^{\text {nd }}$ Edition, 1959, pp.197-202.

${ }^{19}$ Timoshenko, S., and Geer, J.M, “Theory of Elastic Stability," McGraw-Hill, New York, Reprinted by Dover, New York, $2^{\text {nd }}$ Edition, 1989, pp.1-45, pp.362-367.

${ }^{20}$ SolidWorks and SolidWorks Simulation User Manual 2011, SolidWorks Corporation, Dassault Systèmes, Concord, Massachusetts.

${ }^{21}$ Niu, M. C. Y., "Airframe Structural Design," Conmilit Press Ltd., Hong Kong, 1993, pp. 376-428. 